\title{
MAMAP - a new spectrometer system for column-averaged methane and carbon dioxide observations from aircraft: instrument description and performance analysis
}

\author{
K. Gerilowski ${ }^{1}$, A. Tretner ${ }^{2}$, T. Krings ${ }^{1}$, M. Buchwitz ${ }^{1}$, P. P. Bertagnolio ${ }^{1, *}$, F. Belemezov ${ }^{1}$, J. Erzinger ${ }^{2}$, \\ J. P. Burrows ${ }^{1}$, and H. Bovensmann ${ }^{1}$ \\ ${ }^{1}$ University of Bremen, Institute of Environmental Physics, P.O. Box 330440, 28334 Bremen, Germany \\ ${ }^{2}$ Helmholtz Centre Potsdam - GFZ German Research Centre for Geosciences, Telegrafenberg, 14473 Potsdam, Germany \\ *now at: University of Siena, Department of Earth Sciences, Via Laterina 8, 53100 Siena, Italy
}

Received: 9 July 2010 - Published in Atmos. Meas. Tech. Discuss.: 2 August 2010

Revised: 13 January 2011 - Accepted: 22 January 2011 - Published: 10 February 2011

\begin{abstract}
Carbon dioxide $\left(\mathrm{CO}_{2}\right)$ and Methane $\left(\mathrm{CH}_{4}\right)$ are the two most important anthropogenic greenhouse gases. $\mathrm{CH}_{4}$ is furthermore one of the most potent present and future contributors to global warming because of its large global warming potential (GWP). Our knowledge of $\mathrm{CH}_{4}$ and $\mathrm{CO}_{2}$ source strengths is based primarily on bottom-up scaling of sparse in-situ local point measurements of emissions and upscaling of emission factor estimates or top-down modeling incorporating data from surface networks and more recently also by incorporating data from low spatial resolution satellite observations for $\mathrm{CH}_{4}$. There is a need to measure and retrieve the dry columns of $\mathrm{CO}_{2}$ and $\mathrm{CH}_{4}$ having high spatial resolution and spatial coverage. In order to fill this gap a new passive airborne 2-channel grating spectrometer instrument for remote sensing of small scale and mesoscale column-averaged $\mathrm{CH}_{4}$ and $\mathrm{CO}_{2}$ observations has been developed. This Methane Airborne MAPper (MAMAP) instrument measures reflected and scattered solar radiation in the short wave infrared (SWIR) and near-infrared (NIR) parts of the electro-magnetic spectrum at moderate spectral resolution. The SWIR channel yields measurements of atmospheric absorption bands of $\mathrm{CH}_{4}$ and $\mathrm{CO}_{2}$ in the spectral range between 1.59 and $1.69 \mu \mathrm{m}$ at a spectral resolution of $0.82 \mathrm{~nm}$. The NIR channel around $0.76 \mu \mathrm{m}$ measures the atmospheric $\mathrm{O}_{2}$-A-band absorption with a resolution of $0.46 \mathrm{~nm}$. MAMAP has been designed for flexible operation aboard a variety of airborne platforms. The instrument
\end{abstract}

Correspondence to: K. Gerilowski (gerilows@iup.physik.uni-bremen.de) design and the performance of the SWIR channel, together with some results from on-ground and in-flight engineering tests are presented. The SWIR channel performance has been analyzed using a retrieval algorithm applied to the nadir measured spectra. Dry air column-averaged mole fractions are obtained from SWIR data only by dividing the retrieved $\mathrm{CH}_{4}$ columns by the simultaneously retrieved $\mathrm{CO}_{2}$ columns for dry air column $\mathrm{CH}_{4}\left(\mathrm{XCH}_{4}\right)$ and vice versa for dry air column $\mathrm{CO}_{2}\left(X_{C_{2}}\right)$. The signal-to-noise ratio (SNR) of the SWIR channel is approximately 1000 for integration times $\left(t_{\text {int }}\right)$ in the range of $0.6-0.8 \mathrm{~s}$ for scenes with surface spectral reflectances (SSR)/albedo of around 0.18. At these integration times the ground scene size is about $23 \times 33 \mathrm{~m}^{2}$ for an aircraft altitude of $1 \mathrm{~km}$ and a ground speed of $200 \mathrm{~km} / \mathrm{h}$. For these scenes the actual $\mathrm{XCH}_{4}$ or $\mathrm{XCO}_{2}$ dry air column retrieval precisions are typically about $1 \%(1 \sigma)$. Elevated levels of $\mathrm{CH}_{4}$ have been retrieved above a $\mathrm{CH}_{4}$ emitting landfill. Similarly the plume of $\mathrm{CO}_{2}$ from coal-fired power plants can be well detected and tracked. The measurements by the MAMAP sensor could enable estimates of anthropogenic, biogenic and geological emissions of localized intense $\mathrm{CH}_{4}$ and $\mathrm{CO}_{2}$ sources such as anthropogenic fugitive $\mathrm{CH}_{4}$ emissions from oil and gas industry, coal mining, disposal of organic waste, $\mathrm{CO}_{2}$ emissions from coal-fired power plants, steel production or geologic $\mathrm{CH}_{4}$ and $\mathrm{CO}_{2}$ emissions from seepage and volcanoes. Appropriate analysis of the measurements of MAMAP potentially also yields natural $\mathrm{CH}_{4}$ emissions from less intense but extensive sources such as wetlands.

Published by Copernicus Publications on behalf of the European Geosciences Union. 


\section{Introduction}

Carbon dioxide $\left(\mathrm{CO}_{2}\right)$ and methane $\left(\mathrm{CH}_{4}\right)$ are the two most important anthropogenic greenhouse gases (GHG) contributing to climate change (IPCC, 2007, 2001; Wuebbles and Hayhoe, 2002). In addition $\mathrm{CH}_{4}$ plays an important role in the chemistry cycle of the atmosphere (Rice et al., 2003; Wuebbles and Hayhoe, 2002; IPCC, 2001). Despite their importance, our knowledge about their natural and anthropogenic sources (and sinks) has significant gaps (IPCC, 2007; Wuebbles and Hayhoe, 2002). This arises in part because of the difficulty in estimating the highly spatially and temporally variable natural and anthropogenic atmospheric source emissions (IPCC, 2007, 2001; Watson et al., 1990).

Up to now, flux estimates of $\mathrm{CH}_{4}$ and $\mathrm{CO}_{2}$ of current global, synoptic, and mesoscale 3-D chemical transport and climate models (CTM and CM) are based on either bottomup or top-down approaches. Bottom-up flux estimates of anthropogenic sources are typically compiled by national authorities by the assessments of economic statistical data or by emission factor estimates using a variety of procedures (NRC, 2010). For bottom-up flux estimates of natural sources, ground-based microscale measurements are collected from a variety of different techniques, such as closed chamber and eddy covariance methods (Sachs et al., 2008, and references therein). Emission and flux estimates obtained by these techniques are typically assigned to specific soil/vegetation types and then are spatially extrapolated to meso and synoptic scales using, for example, a global vegetation index, derived from satellite imaging data (Takeuchi et al., 2003).

In contrast global, synoptic, and mesoscale top-down emission estimates are based on precise and accurate atmospheric in-situ concentration measurements of the relevant gases from surface networks, tall towers, helicopters, aircrafts, and trains (Dlugokencky et al., 1995, 2005; Winderlich et al., 2010; Matsueda and Inoue, 1999; Jagovkina et al., 2000; Oberlander et al., 2002; Nisbet, 2005; Miller et al., 2007; Kort et al., 2008). These measurements are then inverted by inverse models to estimate flux rates between the surface and the atmosphere (Jagovkina et al., 2001; Chen and Prinn, 2006; Bergamaschi et al., 2005, 2007). Natural and anthropogenic bottom-up flux estimates are often input into the inversion calculations. Based on the measured data the anthropogenic and natural fluxes are modified during the inversion calculation (Chen and Prinn, 2006; Bergamaschi et al., 2005, 2007; Jagovkina et al., 2000), in a way that the simulated atmospheric concentrations better match the observations. As a result of the coarse density of the surface observation network, information about surface fluxes distant from the network is still not well defined and ambiguous (Villani et al., 2010; Bréon and Ciais, 2010; NRC, 2010). Especially discrimination of the different source types remains still inaccurate (NRC, 2010).
With the launch of the European environmental satellite, ENVISAT, with the SCIAMACHY instrument on board (Bovensmann et al., 1999; Burrows et al., 1995), dry column averaged air mole fractions of $\mathrm{CH}_{4}$, and $\mathrm{CO}_{2}, \mathrm{XCH}_{4}$, and $\mathrm{XCO}_{2}$ respectively, could be derived from space with a typical footprint of $60 \mathrm{~km} \times 30 \mathrm{~km}$. The SCIAMACHY $X \mathrm{CH}_{4}$ (Buchwitz et al., 2000, 2005a,b, 2006; Frankenberg et al., 2005; Schneising et al., 2009) and $\mathrm{XCO}_{2}$ (Buchwitz et al., 2000, 2005a,b, 2006; Schneising et al., 2008) are retrieved from back scattered solar electromagnetic radiation in the Near Infrared, NIR, and Short Wave Infrared, SWIR, spectral regions. This radiation carries information about the absorption in the atmosphere and has high sensitivity down to the boundary layer including the Earth's surface.

These new remote sensing data were incorporated for the first time to estimate the annual $\mathrm{CH}_{4}$ surface fluxes at a resolution of several degrees using top-down inverse modeling (Bergamaschi et al., 2007, 2009). Recently a new mission for GHG observations, the GOSAT satellite with the Tanso-FTS on board (Yoshida et al., 2008), was launched successfully in January 2009. The footprint of the Tanso-FTS instrument is $10 \mathrm{~km}$ in diameter with a typical gap for nominal mode of about $160 \mathrm{~km}$ (adjusted recently to $320 \mathrm{~km}$ ) between observations. Because SCIAMACHY's and GOSAT large typical footprint (i.e. $60 \mathrm{~km} \times 30 \mathrm{~km}$ for SCIAMACHY and $10 \mathrm{~km}$ diameter for GOSAT), and the large gaps between the typical measurements of GOSAT single local emissions cannot be accurately resolved in the currently available satellite data (Bréon and Ciais, 2010). Therefore the contribution of small "hot-spot" areas and single facilities is not sufficiently resolved with the existing ground-based and satellite observational systems (NRC, 2010). Future satellite missions like OCO-2 with its reduced footprint sizes of $3.4 \mathrm{~km}^{2}$ will partly overcome this problem for $\mathrm{CO}_{2}$ (Crisp et al., 2009). In contrast $\mathrm{CH}_{4}$ will not be sufficiently resolved in currently approved future satellite missions.

The deficiencies in our current knowledge of point sources and "hot-spot" areas emerge a clear need for the development of new measurement techniques to improve top-down estimates and constrain regional and local emissions (NRC, 2010). These techniques are needed to extend the coverage and facilitate the integration of existing global systems and address the up-scaling issue. In this respect, airborne passive and active remote sensing techniques offer potentially a unique set of opportunities, as they combine coverage with high spatial resolution. The measured data ideally need to be of an accuracy and precision to yield on inversion the $\mathrm{CH}_{4}$ and $\mathrm{CO}_{2}$ emissions from less intense but extensive and larger scale sources (and sinks), such as wetlands. As a threshold the accuracy and precision of the data yield on inversion significant constraints on local hot spot emissions to separate them from the less intense but extensive larger scale sources (and sinks) and thereby allowing an improved estimate of both. 
Until recently, there was a lack of dedicated airborne instrumentation with the capability of measuring $\mathrm{CH}_{4}$ and $\mathrm{CO}_{2}$ dry atmospheric columns (mole fractions) within or above the planetary boundary layer (NRC, 2010) with sufficient relative accuracy and precision required for those applications. Active $\mathrm{CH}_{4}$ systems measuring column concentration (not to confuse with mole fractions) designed for pipeline leakage detection and monitoring (Meyer et al., 2006; Zimig and Ulbricht, 2006; Ershov, 2007) are typically limited to altitudes below $300 \mathrm{~m}$ while recommended operation altitudes range typically around $100 \mathrm{~m}$. Due to the altitude limitation those systems are actually not well adopted for local scale atmospheric applications requiring atmospheric dry column measurements up to et least the height of the planetary boundary layer which can reach in summer a height of up to $2000 \mathrm{~m}$. It is reported in literature that active DIAL pipeline monitoring instruments reach a $\mathrm{CH}_{4}$ column concentration threshold sensitivity during flights at typical flight altitudes of $100 \mathrm{~m}$ in the range of $80 \mathrm{ppm} \mathrm{m}^{1}$ (for ground based laboratory measurements) (Meyer et al., 2006) and $100 \mathrm{ppm}$ m (airborne at $0.5 \mathrm{~s}$ measurement time) (Ershov, 2007). Recent developments of high altitude DIAL systems for airborne GHG dry column measurements are ongoing in the framework of future satellite developments but not yet available for field application (NRC, 2010).

For passive systems designed for atmospheric applications like the airborne SWIR FTS developed for GOSAT validation and calibration (Suto et al., 2008) dry air column precisions and "in-flight" detection limits have not yet been published. Passive instruments for gas leakage monitoring (like reported by Meyer et al., 2006) based on a compact $1 / 4 \mathrm{~m}$ polychromator working in the $1.60 \mu \mathrm{m}$ to $1.68 \mu \mathrm{m}$ spectral range have a reported detection limit of the measured column concentration of $800 \mathrm{ppm}$ m (ca. 5\% total column, referred to a $1013 \mathrm{hPa}$ normalized total atmospheric thickness of about $8580 \mathrm{~m}$, see Sect. 4.3.4). Roberts et al. (2010) also reported recent successful trials adapting retrieval algorithms for hyperspectral imaging data of the Airborne Visible Infrared Imaging Spectrometer (AVIRIS) to map $\mathrm{CH}_{4}$ emissions over strong marine geological $\mathrm{CH}_{4}$ sources reaching theoretical detection limits for measurements in solar glint of $36 \mathrm{ppb} \mathrm{CH}_{4}$ total column increase (corresponding to $300 \mathrm{ppm} \mathrm{m}$ ) for the resulting $\mathrm{CH}_{4}$ maps. For smaller surface spectral reflectance $(\mathrm{SSR})($ i.e. $<0.22)$ the detection limit degrades proportionately with the decreasing radiance (Roberts et al., 2010). It is expected that $\mathrm{CO}_{2}$ and $\mathrm{CH}_{4}$ retrieval from terrestrial, low spectral resolution hyperspectral data is much more demanding as a result of the need to model accurately the SSR to reduce the uncertainty in the retrieved $\mathrm{CH}_{4}$ and $\mathrm{CO}_{2}$ column concentrations. For both passive systems (gas leakage monitoring an hyperspectral) airborne dry air column precisions have not been reported either.

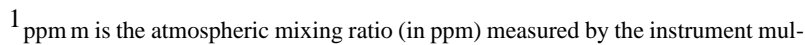
tiplied by the equivalent atmospheric absorption light path calculated for standard conditions of temperature and pressure.
}

In order to close the existing gap not accommodated by currently available instrumentation and to validate spacebased measurements on local and meso scales (i.e. from SCIAMACHY and GOSAT) a team from the University of Bremen and the Helmholtz Centre Potsdam, German Research Centre for Geosciences (GFZ), have developed an airborne spectrometer system, capable of direct and quantitative remote column-averaged measurements of atmospheric $\mathrm{CH}_{4}$ and $\mathrm{CO}_{2}$. This system, named the "Methane Airborne MAPper" (MAMAP), is designed for flexible operations on a variety of airborne platforms, and is described in detail below. MAMAP is equipped with a down-looking telescope for nadir observations and an up-looking light inlet for zenith observations. The MAMAP aircraft instrument was designed to measure total vertical columns of $\mathrm{CH}_{4}$ and $\mathrm{CO}_{2}$ on small spatial scales $(<250 \mathrm{~m})$ with a precision and relative accuracy equal or better than $1-2 \%$ (threshold $<2 \%$, target $<1 \%$ ) dry atmospheric column for altitudes of at least the height of the planetary boundary layer (i.e. up to $2000 \mathrm{~m}$ ) over land for typical albedo/SSR of about 0.18 . This precision/relative accuracy requirement corresponds to a column enhancement of about 150-300 ppm m below the aircraft which places limitations on the measurable target emission strengths (see Sect. 5). The initial instrument precision threshold specifications were inferred primarily from flux estimates of strong anthropogenic and geologic methane emitters with large emission uncertainties. The emitters considered include for instance large landfills with $\mathrm{CH}_{4}$ emissions equal or greater then 5-10 $\mathrm{ktCH}_{4} \mathrm{yr}^{-1}$ (EPER, 2004), fugitive emissions from entire gas fields/deposits like reported by Jagovkina et al. (2000, and references therein) with emission estimates between 2 and $10 \mathrm{MtCH}_{4} \mathrm{yr}^{-1}$ for an area of about $1.8 \times 10^{10} \mathrm{~m}^{2}$, emissions from coal mining facilities reported to reach up emissions $>20 \mathrm{ktCH}_{4} \mathrm{yr}^{-1}$ on local scales (EPER, 2004), or geologic emissions from marine methane bearing sediments in arctic regions were atmospheric concentrations (measured $2 \mathrm{~m}$ above ground) can reach values between 3 and $8 \mathrm{ppm}$ with respect to the atmospheric background concentration of 1.85 ppm over areas with the extend of several square kilometers (Shakhova et al., 2007, 2010). The instrument precision goal requirements of $\leq 1 \%$ dry atmospheric column allows measurements of localized emitters or single facilities with even smaller emissions (i.e. $<5 \mathrm{ktCH}_{4} \mathrm{yr}^{-1}$, see Sect. 5).

Due to the large uncertainties of $\mathrm{CH}_{4}$ emissions of different local anthropogenic and geologic sources (NRC, 2010) measurements with MAMAP have also the potential to topdown constrain bottom-up estimates from those types of sources (see Sects. 5 and 6). For instance Chambers and Strosher (2006a,b) reported 4-9 times higher emissions for Canadian refineries and natural gas processing plans when measured with ground based DIAL than calculated by emission factors of the single components. Börjesson et al. (2000) found that, for the same landfill, $\mathrm{CH}_{4}$ emissions were a factor of 4 higher, when estimated using a tracer gas technique, 
than that bottom-up estimated from closed chamber measurements. Anthropogenic Methane emissions from fossil fuel industry (coal, natural gas and oil) and landfills are estimated to be responsible for about 167 (86-274) $\mathrm{MtCH}_{4} \mathrm{yr}^{-1}$ with respect to total global natural $\mathrm{CH}_{4}$ wetland emissions estimated to be about $100(91-232) \mathrm{MtCH}_{4} \mathrm{yr}^{-1}$ compared to total global $\mathrm{CH}_{4}$ emissions (anthropogenic and natural) estimated to be about 503 (410-660) $\mathrm{Mt} \mathrm{CH}_{4} \mathrm{yr}^{-1}$ (Wuebbles and Hayhoe, 2002).

Even though the goal and threshold requirements for MAMAP were initially inferred primarily for $\mathrm{CH}_{4}$ they will also allow measurements of strong anthropogenic $\mathrm{CO}_{2}$ emitters with typical emissions between $1-30 \mathrm{MtCO}_{2} \mathrm{yr}^{-1}$ like coal fired power plants (as demonstrated in Sect. 3), steelworks, cement production etc. (EPER, 2004) or geologic emitters like volcanoes (Mörner and Etiope, 2002). Ackerman and Sundquist (2008) compared powerplant (PP) emission data bases and found that the absolute difference of the emissions of individual coal-fired PPs in the USA is typically about $20 \%$. Thus instruments like MAMAP can potentially be used for independent monitoring (for inversion modeling of PP emissions with MAMAP measurements and associated uncertainties, see also Krings et al., 2011). Reaching the goal precision and relative accuracy of $\leq 1 \%$ will potentially allow $\mathrm{CO}_{2}$ measurements and top-down emission estimates for major cities having even larger uncertainties of the emissions (NRC, 2010). Appropriate analysis of the measurements of MAMAP potentially also yields natural $\mathrm{CH}_{4}$ emissions from less intense but extensive sources such as wetlands.

In the following the MAMAP instrument design and the performance together with some results from on-ground and in-flight engineering tests are presented. The analysis is focused primarily on the most important instrument parameters i.e. signal to noise ratio (SNR), associated precision and spectral stability. Furthermore the analysis is limited to the SWIR cannel and associated $\mathrm{XCH}_{4}$ or $\mathrm{XCO}_{2}$ products derived from SWIR data only. A discussion of systematic effects and the overall uncertainty of the data products will be given in a separate publication (i.e. Krings et al., 2011). Alternative retrieval strategies incorporating $\mathrm{O}_{2}$ data from NIR measurements and associated concurrent $\mathrm{XCH}_{4}$ and $\mathrm{XCO}_{2}$ products will be discussed elsewhere.

This manuscript is organized as follows: in Sect. 2 the MAMAP instrument is described and its specifications are given. The current version of the MAMAP retrieval algorithm, which has been used to assess the on-ground and inflight instrument performance, is briefly explained in Sect. 3 . In Sect. 4 the results of the MAMAP instrument performance analysis are presented and discussed. In Sect. 5 relevant $\mathrm{CH}_{4}$ and $\mathrm{CO}_{2}$ emission targets are discussed. In Sect. 6 first results are shown from the analysis of flights near or over anthropogenic $\mathrm{CO}_{2}$ and $\mathrm{CH}_{4}$ emission sources. Finally, a summary is given in Sect. 7 .
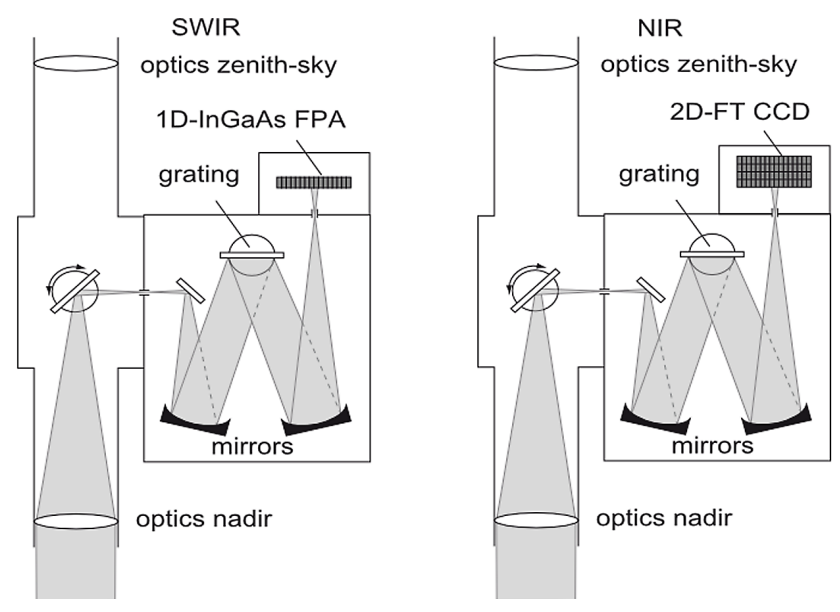

Fig. 1. Sketch of the MAMAP SWIR and NIR spectrometer modules. Both spectrometers have two separate light intake telescopes pointing towards nadir and zenith-sky directions for measurements of nadir and zenith radiances. A mirror enables switching between both modes. For zenith irradiance measurements zenith optics can be equipped optionally with glass fibers and transmissive diffuser optical inlets (not shown in this sketch).

\section{Description of the MAMAP instrument}

The MAMAP instrument comprises two thermally stabilized grating spectrometer systems having a focal length of $F=300 \mathrm{~mm}$ and a f-number of $\mathrm{f} / 3.9$. One (non-imaging) spectrometer system measures in the SWIR over the spectral region at $1590-1690 \mathrm{~nm}$ to enable simultaneous retrieval of $\mathrm{CO}_{2}(1590-1620 \mathrm{~nm})$ and $\mathrm{CH}_{4}(1630-1750 \mathrm{~nm})$ columns. The second push-broom imaging spectrometer system measures in the NIR over the spectral region between 756$769 \mathrm{~nm}$ for the detection of the oxygen $\left(\mathrm{O}_{2}\right)$ absorption using the $\mathrm{O}_{2}$-A band. The retrieved $\mathrm{O}_{2}$ columns can be used to convert the greenhouse gas columns into dry-air columnaveraged mixing ratios (see Sect. 3).

Both spectrometers have two independent telescopes, collecting electromagnetic radiation, and pointing towards nadir and upwards to the zenith-sky direction (Figs. 1 and 2). A fold-mirror allows switching between the nadir and zenithsky modes of operation. This permits sequential measurement of the diffuse up-welling and down-welling radiance. Optionally, cosine diffuser plates or a combination of cosine diffuser plates plus glass fibres and collimator optics can be installed on-top of the zenith sky telescopes. In this configuration the instrument can perform direct solar irradiance measurements and diffuse down-welling (ir)radiance measurements in zenith-sky mode. From these measurements total and/or partial vertical columns can be retrieved as will be described in Sect. 3.

The instrument is designed to operate at altitudes of more than $20 \mathrm{~km}$ from pressurized cabins and up to $4 \mathrm{~km}$ in non-pressurized cabins allowing measurements to above the 

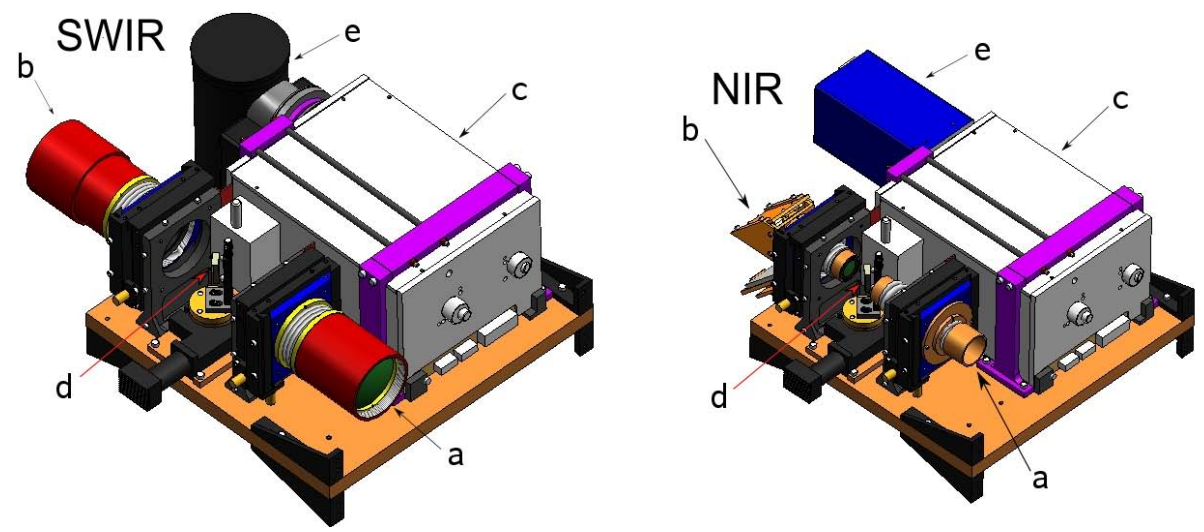

Fig. 2. CAD drawing of the SWIR (left) and NIR (right) spectrometer modules. (a) nadir optics, (b) zenith-sky optics (equipped with telescopes for radiance measurements), (c) spectrometer housing, (d) automated fold mirror, (e) SWIR/NIR detector heads.

convective boundary layer (CBL). Furthermore, it achieves a ground scene of $<300 \mathrm{~m}$ (along the flight track) on high altitude aircrafts with cruise speeds around $900 \mathrm{~km} \mathrm{~h}^{-1}$. Depending on cruise speed, pixel sizes range typically between $<50$ and $150 \mathrm{~m}$ on slower $\left(<400 \mathrm{~km} \mathrm{~h}^{-1}\right)$ propeller aircrafts.

\subsection{The $\mathrm{CH}_{4} / \mathrm{CO}_{2} \mathrm{SWIR}$ spectrometer}

A single non-imaging grating SWIR spectrometer is utilized to simultaneously retrieve $\mathrm{CH}_{4}$ and $\mathrm{CO}_{2}$. This spectrometer uses a special $F=300 \mathrm{~mm}$ modulation transfer function (MTF) optimised aspheric doublet lens (manufactured by ZEISS) for nadir observations and a single spherical lens $(F=300 \mathrm{~mm})$ for zenith-sky observations. The instantaneous field of view (IFOV) of the SWIR spectrometer is $1.34^{\circ}$ across track (CT) and $0.02^{\circ}$ along the flight track (LT).

The sensor head of the SWIR spectrometer is a modified linear photodiode array camera from Princeton Instruments (OMA-5, LN-1024) using a linear extended InGaAs 1024 pixel focal plane array (FPA) as detector. The detector is cooled with liquid nitrogen to $-120^{\circ} \mathrm{C}$ to minimise detector noise. With a pixel pitch of $25 \mu \mathrm{m}$, this array covers $25.6 \mathrm{~mm}$ in the spectral direction of the spectrometer's focal plane. In combination with a 600 grooves $\mathrm{mm}^{-1}$ spectrometer grating, a spectral window of $97.3 \mathrm{~nm}$ can be covered with a spectral resolution of about $0.82 \mathrm{~nm}$ (FWHM). At this resolution a sampling of approximately 8.6 detector pixels per FWHM is achieved. The coverage of a $97.3 \mathrm{~nm}$ spectral window permits the simultaneous measurement of $\mathrm{CH}_{4}$ and $\mathrm{CO}_{2}$ absorption bands with the same detector.

The detector/camera non-linearity was provided by the manufacturer and stated to be $<1 \%$. The slit function of the system on different detector positions was measured with a single line from a spectral line source (SLS) while rotating the motorized grating slightly in different positions. The FWHM was then fitted by two Gaussian line shapes and slightly adjusted while minimizing the fit residuum (see Sect. 3). Spectral calibration was inferred by shift end squeeze until optimal matching of the absorber features can be achieved (see Sect. 3). Due to the high sampling of 8.6 detector pixels per FWHM sufficient good results can be achieved by the approach. The system was currently not absolutely calibrated. Nevertheless throughput of the system was inferred with limited accuracy from laboratory tests and from manufacturer throughput data of the single optical components.

The dark signal of the sensor was reduced from $\sim 600 \mathrm{fA}$ to below $60 \mathrm{fA}$ measured at an optical bench temperature of $25^{\circ} \mathrm{C}$ by modifying the camera head. With the full well capacity of a single detector pixel of about $4.4 \mathrm{Me}^{-}$ this dark signal reduction yields a theoretical signal to noise ratio (SNR) of 1000 and higher over land (surface albedo/SSR $=0.18$, detector exposure time $t_{\exp } \sim 0.6 \mathrm{~s}$ ) and a SNR of larger than 350 over water (albedo/SSR $\sim 0.01$, $t_{\exp } \sim 3-5 \mathrm{~s}$ ). Details concerning the SNR estimates are given in Sect. 4. To prevent detector saturation for high albedo/SSR scenes at nominal operation, the exposure time for a single readout is typically reduced by a factor of 10 (from $580 \mathrm{~ms}$ to $58 \mathrm{~ms}$ ) over land and to $1-2 \mathrm{~s}$ over water. Over land, bursts of typically 10 single detector-readouts are collected and stored. All single readouts of each burst are then co-added in order to reach an appropriate SNR. This mode of operation is referred to as "co-added burst mode". For a flight altitude of $1 \mathrm{~km}$, a surface albedo/SSR of 0.18 and a flight speed of $\sim 200 \mathrm{~km} \mathrm{~h}^{-1}$ (e.g., Cessna 207 aircraft), a co-added ground pixel size of $23.4 \mathrm{~m}$ (cross track, CT) $\times 33 \mathrm{~m}$ (along track, LT) can be achieved for a total co-adding/integration time of $\sim 0.6 \mathrm{~s}$.

\subsection{The $\mathrm{O}_{2}$-A-band NIR spectrometer}

A push-broom imaging NIR spectrometer system, operating in the 756 to $769 \mathrm{~nm}$ spectral range detects $\mathrm{O}_{2}$. It uses two $F=80 \mathrm{~mm}$ lens doublets for nadir and zenith sky operation.

The IFOV is $5.85^{\circ}(\mathrm{CT}) \times 0.072^{\circ}(\mathrm{LT})$. In the CT direction, the IFOV is approximately 4 times larger than the IFOV 


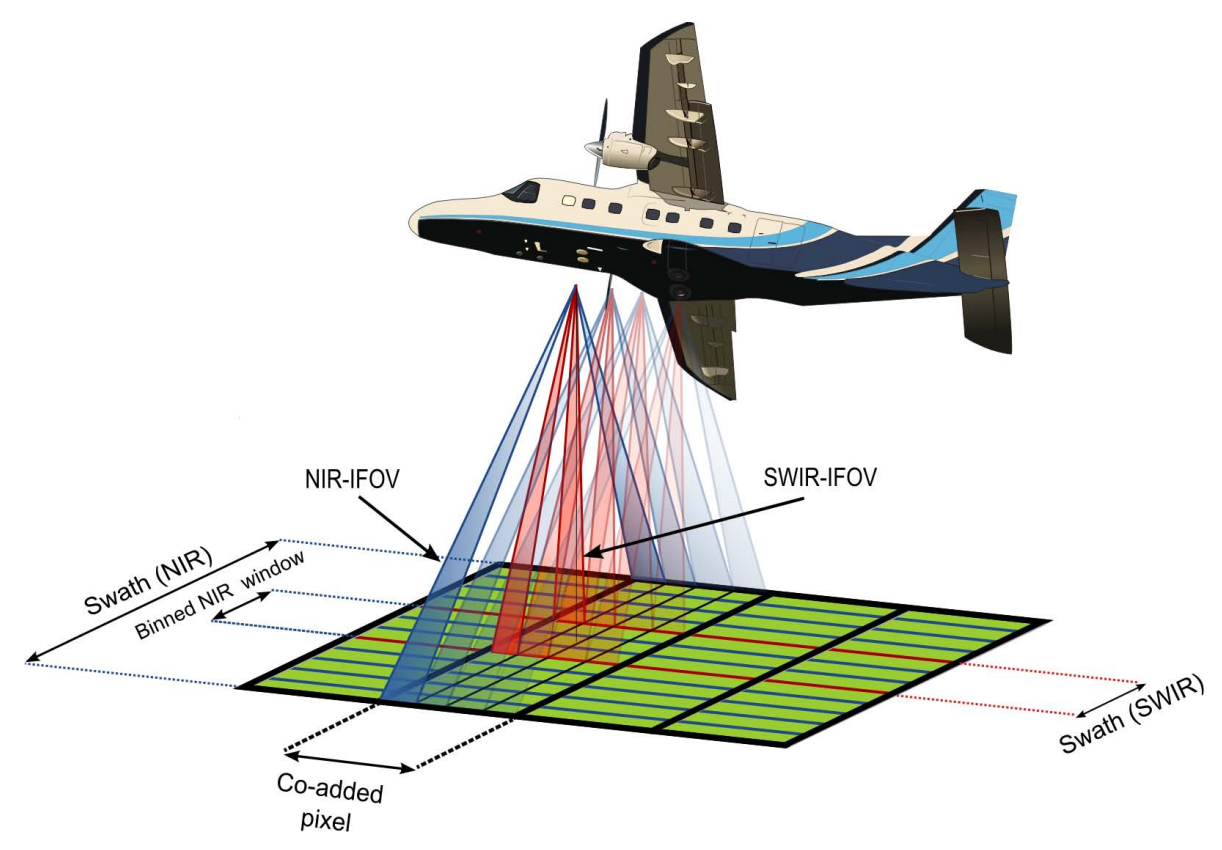

Fig. 3. MAMAP observation geometry for the 1-D-SWIR (red) and the 2-D imaging NIR (blue) spectrometer.

of the SWIR spectrometer. This larger IFOV was chosen to allow characterization of the surrounding scene. In imaging direction (CT) the NIR IFOV is subdivided in 85 discrete pixels. During post processing, approximately $1 / 4$ of these 85 detector pixels is software binned to a window for each detector reading. In this manner, a single 1-D-spectral readout can be created which can be matched to the IFOV of the (1-D) SWIR spectrometer. To optimally match both IFOV (see Fig. 3) the binned NIR-IFOV window can be moved in CT direction during post processing, until optimum co-alignment to the SWIR IFOV is achieved. Due to both spectrometers small IFOV in the LT (i.e., flight-) direction small misalignments of both slits in LT direction are not critical as the LT pixel size is defined primarily by the total co-adding/integration time of each burst. Sufficient good co-boresighting of both slits in LT direction was achieved by moving a small source inside the IFOV of both systems and by imaging a slit in infinity onto both input lenses of the system. Both spectrometer slits were then aligned with respect to the imaged slit. Sufficiently good LT synchronisation of the pixels for both spectrometers is achieved by electronic synchronisation of the exposure times and the detector readouts.

The NIR $\mathrm{O}_{2}$-A spectrometer system uses an E2V $512 \times 512$ pixel frame transfer (FT) CCD with a pixel pitch of $16 \mu \mathrm{m} \times 16 \mu \mathrm{m}$ as detector. The detector/camera nonlinearity provided by the manufacturer is stated to be $<0.3 \%$. The detector is cooled to $-30^{\circ} \mathrm{C}$ by thermoelectric coolers, to minimise the detector noise. To speed up the readout time and reduce the data output, 6 pixels in imaging and 2 pixel in spectral direction are hardware binned, resulting in an array of 85 (spatial) and 256 (spectral) pixels with a pixel size of 96 by $32 \mu \mathrm{m}$. The readout of the FT-CCD is fully hardware synchronized with the readout of the SWIR detector by trigger pulses. The FT-CCD covers $8.192 \mathrm{~mm} \times 8.192 \mathrm{~mm}$ of the - push-broom - imaging spectrometers focal plane. In combination with a 1200 grooves $\mathrm{mm}^{-1}$ spectrometer grating, a spectral window of $13 \mathrm{~nm}$ can be imaged on the detector, resulting in a spectral resolution of $\sim 0.46 \mathrm{~nm}$ (FWHM). With the (binned) pixel size of $32 \mu \mathrm{m}$ (in spectral direction) a sampling of $\sim 9$ pixels per FWHM is achieved. Respectively, hardware binning of 6 pixels in imaging direction, divides the NIR spectrometers field of view in the mentioned 85 pixels (CT). For an albedo/SSR of $\sim 0.18$, detector fillings in the range of $50-70 \%$ are achieved for an exposure time of $\sim 0.6-0.8 \mathrm{~s}$. With the full well capacity of $1560 \mathrm{ke}^{-}$for a single hardware binned $(6 \times 2)$ detector pixel, theoretical SNR values of $\sim 1000$ per (binned) pixel can be achieved. In order to prevent detector saturation for high albedo/SSR scenes, the single readout exposure time is also reduced by a factor of 10 (as for the SWIR detector). Thus, a typical burst of 10 single detector-readouts are collected and stored (and later co-added).

The $(6 \times 2)$ binned pixel SNR was further increased by additional binning in across flight direction on the cost of spatial resolution. For example, CT software binning of all pixels of the NIR channel within the IFOV of the SWIR channel (i.e. $\sim 1 / 4$ of the 85 NIR spectrometer pixels, see Fig. 3), will result in a theoretical SNR of more than 4000 . 


\subsection{Pointing and image navigation}

To monitor the position and the pointing of the instrument, MAMAP is equipped with a Garmin $5 \mathrm{~Hz}$ GPS and a Microstrain 3DM GX1 gyro-system. The readout of the position data of both devices is fully synchronized with the readout of the spectrometers. Additional position logging systems can be synchronized to MAMAP via external triggers. The MAMAP system also contains a triggered $640 \times 480$ pixel $1 / 4^{\prime \prime}$ interline CCD colour camera (type: DFK 21BF04) for image acquisition which is synchronized with the spectrometer sensors. The CCD camera is equipped with a $25 \mathrm{~mm}$ lens and has the IFOV of $7.2^{\circ}(\mathrm{CT}) \times 5.7^{\circ}$ (LT). This optical control helps to optimise the pointing knowledge of the MAMAP system. In this manner, pointing information towards different ground surface types can link $\mathrm{CH}_{4}$ and $\mathrm{CO}_{2}$ column information with potential $\mathrm{CH}_{4}$ or $\mathrm{CO}_{2}$ sources.

\subsection{System control, data acquisition and power supply}

Each SWIR and NIR spectrometer system uses a separate ultra slim, fan-less Advantech S123T panel PC for data acquisition, management of housekeeping data and the spectrometer (zenith/nadir) fold mirror control. For control and data acquisition of the CCD camera, the GPS and the gyro system, a separate embedded PC is used. To avoid data damage over $3000 \mathrm{~m}$ flight altitude in unpressurised aircraft cabins all computers were equipped with flash disk devices for data storage. Thermal stabilization of the system was performed by two "off the shelf" digital PID controller units in combination with thermoelectric heaters. The system is powered through an uninterruptible power supply (UPS) and an optional $28 \mathrm{~V}$ DC to $220 \mathrm{~V}$ AC converter permitting the instrument to be operated either on $28 \mathrm{~V}$ DC or $220 \mathrm{~V} \mathrm{AC}$. The UPS has a GILL 28 V/43 Ah sealed lead acid battery, allowing the instrument to be operated up to $2 \mathrm{~h}$ without external power.

The whole system including all controllers and the batterybuffered power supply fits into two standard (DLR-Falcon) aircraft racks $(556 \mathrm{~mm} \times 650 \mathrm{~mm} \times 968 \mathrm{~mm}$ each $)$. The weight of each rack is approximately $120 \mathrm{~kg}$. The first rack contains the camera controllers, the spectrometers and telescopes with the thermal control unit. The second rack contains the panel and the embedded PC's for the spectrometer control and data acquisition and the UPS system (Fig. 4). It has to be noted that MAMAP is currently not optimised w.r.t. mass, and there is potential for some significant mass reductions if required.

The instrument has been designed for flexible operation on-board a variety of airborne research platforms (e.g., Dornier 228, Dassault Falcon, Cessna Caravan, Basler-DC3 Polar-5 etc.) and provides all needed synchronisation signals for external Gyro and GPS logging systems. The sensor parameters are summarised in Table 1.

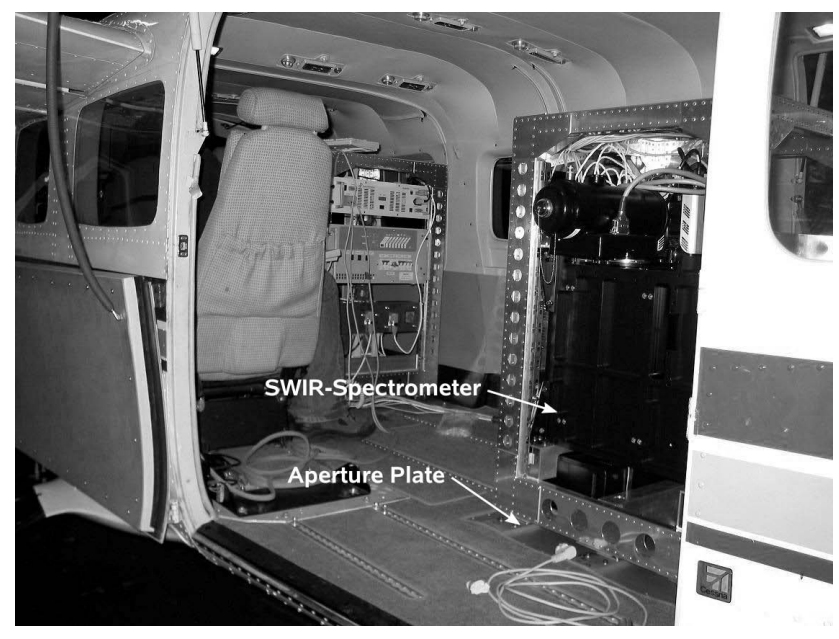

Fig. 4. The MAMAP spectrometer rack mounted on the apertureplate (front) carrying the optics and the spectrometer systems and the MAMAP auxiliary rack (back) carrying the controllers, power converters and the buffer battery (both racks mounted on the RWE Cessna caravan aircraft).

\section{MAMAP retrieval algorithm and the determination of data products}

The objective of the retrieval algorithm is to invert MAMAP spectra to derive the $\mathrm{CH}_{4}, \mathrm{CO}_{2}$ and $\mathrm{O}_{2}$ - total or partial - vertical columns and the $\mathrm{CH}_{4}$ and $\mathrm{CO}_{2}$ column-averaged dry air mixing ratios, $X \mathrm{CO}_{2}$ and $\mathrm{XCH}_{4}$. For the retrieval, measurements of dark signal and pixel to pixel gain corrected (nadir) radiance spectra are used. The measurements and the target quantities being similar with those of the SCIAMACHY satellite instrument on ENVISAT (Buchwitz et al., 2005a,b; Schneising et al., 2008, 2009).

The derivation of the absolute column amounts (in units of number of molecules per unit area, e.g., molecules $\mathrm{cm}^{-2}$ ) into column-averaged dry air mixing ratios (in ppm for $\mathrm{CO}_{2}$ and $\mathrm{ppb}$ for $\mathrm{CH}_{4}$ ) requires knowledge of the corresponding "dry air column", i.e. the total number of molecules in the observed atmospheric column, neglecting water molecules. For the interpretation of the MAMAP measurements the column-averaged mixing ratios are the preferred to the absolute columns, because of their much weaker dependence on the changes of surface topography/pressure and flight altitude. There are several approaches to estimate the dry air column needed for the conversion of the greenhouse gas columns into column-averaged mixing ratios:

i. by the use of the simultaneous measurements of the oxygen $\left(\mathrm{O}_{2}\right)$ column retrieved from spectral measurements of the $\mathrm{O}_{2}$-A band (located at $760 \mathrm{~nm}$ ) analog to the method described in Schneising et al. (2008), for SCIAMACHY column-averaged $\mathrm{CO}_{2}$ retrieval, 
Table 1. MAMAP sensor parameters.

\begin{tabular}{|c|c|}
\hline $\mathrm{CH}_{4} / \mathrm{CO}_{2}$-SWIR-spectrometer & $\mathrm{O}_{2}$-NIR-spectrometer \\
\hline $\begin{array}{l}F=300 \mathrm{~mm} \text { temperature stabilized grating spectrometer system } \\
(\mathrm{f} / 3.9)\end{array}$ & $\begin{array}{l}F=300 \mathrm{~mm} \text { temperature stabilized push broom imaging grating } \\
\text { spectrometer system (f/3.9) }\end{array}$ \\
\hline Grating: 600 grooves $/ \mathrm{mm}^{-1}$ & Grating: 1200 grooves $\mathrm{mm}^{-1}$ \\
\hline Detector: LN cooled 1024 pixel InGaAs FPA & $\begin{array}{l}\text { Detector: } 512 \times 512 \text { pixel CCD Sensor, TE cooled, } 6 \text { pixel } \\
\text { binned in imaging direction and } 2 \text { in spectral direction }\end{array}$ \\
\hline Spectral range: $\sim 1590-1690 \mathrm{~nm}$ & Spectral range: $\sim 756-769 \mathrm{~nm}$ \\
\hline Spectral resolution: $\sim 0.82 \mathrm{~nm}$ FWHM & Spectral resolution: $\sim 0.46 \mathrm{~nm}$ FWHM \\
\hline Spectral sampling: $\sim 8.6 \mathrm{pixel} / \mathrm{FWHM}$ & Spectral sampling: $\sim 9$ pixel/FWHM \\
\hline $\begin{array}{l}\text { Detector-SNR: } \sim 1000 \text { at } \sim 0.6-0.8 \mathrm{~s} \text { integration time }(10 \text { detec- } \\
\text { tor readouts co-added, surface albedo/SSR } 0.18)\end{array}$ & $\begin{array}{l}\text { Detector-SNR: }>4000 \text { (binned) at } \sim 0.6-0.8 \mathrm{~s} \text { integration time } \\
(10 \text { detector readouts co-added, } 1 / 4 \text { of the } 85 \text { spatial rows } \\
\text { binned, surface albedo/SSR } 0.18 \text { ) }\end{array}$ \\
\hline IFOV: $\sim 1.34^{\circ}$ across track $(\mathrm{CT}) \times \sim 0.02^{\circ}$ along track $(\mathrm{LT})$ & $\begin{array}{l}\text { IFOV: } \sim 5.85^{\circ} \text { across track } \quad(\mathrm{CT}, \quad \text { divided } \\
85 \text { pixel }) \times \sim 0.072^{\circ} \text { along track (LT) }\end{array}$ \\
\hline $\begin{array}{l}\text { Spatial resolution: At } 1 \mathrm{~km} \text { flight height, ground speed } \\
200 \mathrm{~km} \mathrm{~h}^{-1} \text { the co-added ground pixel size is } \sim 33 \mathrm{~m} \text { along } \\
\text { track over land (surface albedo/SSR } 0.18 \text { ) and larger for lower } \\
\text { albedo/SSR surfaces. Across track the pixel size is } \sim 23.4 \mathrm{~m}\end{array}$ & $\begin{array}{l}\text { Spatial resolution: At } 1 \mathrm{~km} \text { flight height, ground speed of } \\
200 \mathrm{~km} \mathrm{~h}^{-1} \text { the co-added ground pixel size is } \sim 33 \mathrm{~m} \text { along } \\
\text { track over land (surface albedo/SSR } 0.18 \text { ) and larger for lower } \\
\text { albedo/SSR surfaces. Across track the pixel size is } \sim 102.2 \mathrm{~m} \\
\text { (divided by } 85 \text { ) }\end{array}$ \\
\hline \multicolumn{2}{|c|}{$\begin{array}{l}\text { Precision requirement: Goal: better than } 1 \% \text { of the total } \mathrm{CH}_{4} \text { over } \mathrm{CO}_{2} \text { column-averaged dry air mixing } \\
\text { ratio with respect to the atmospheric background; threshold: better than } 2 \% \text { (precision is defined as the } \\
\text { random error of the retrieved } \mathrm{CH}_{4} \text { and } \mathrm{CO}_{2} \text { columns due to instrument noise) } \\
\text { Size: } 2 \text { "Falcon" standard racks, } 556 \mathrm{~mm} \times 650 \mathrm{~mm} \times 968 \mathrm{~mm} \text { each } \\
\text { Weight: } \sim 120 \mathrm{~kg} \text { (each rack) } \\
\text { Power consumption: } \sim 600-800 \text { Watt at nominal operation, }<1000 \text { Watt at warm-up }\end{array}$} \\
\hline
\end{tabular}

ii. by using another, well mixed gas whose mixing ratio is well enough known and varies less than the trace gas of interest (e.g. by using the simultaneously retrieved $\mathrm{CO}_{2}$ column for normalizing the retrieved $\mathrm{CH}_{4}$ columns to obtain the column averaged mixing ratio of $\mathrm{CH}_{4}$, Frankenberg et al., 2005; Schneising et al., 2009) (or vice versa for $\mathrm{CO}_{2}$ ), and

iii. by using external information on surface pressure obtained from, e.g., meteorological analysis by analogy to the method described in Barkley et al. (2006), for column-averaged $\mathrm{CO}_{2}$ retrieval. However this is problematic since knowledge of surface pressure on a scale of a few meters would be required.

The advantage of the first approach is that the mixing ratio of $\mathrm{O}_{2}$ in dry air is well known $(20.95 \%)$ and constant up to about $100 \mathrm{~km}$ and comprises $99.99 \%$ of the atmosphere. However, differences in the radiative transfer of the electromagnetic radiation through both absorption and scattering result in the path of radiation through the atmosphere being dependent on wavelength. Consequently, the presence of scattering by aerosols, cirrus or other clouds, gives a somewhat different light paths around $760 \mathrm{~nm}$ in comparison to $1.6 \mu \mathrm{m}$, as the phase function for particle scattering depends on wavelength (see Schneising et al., 2008, 2009; Schneising, 2009, for a discussion of this approach). In order to use the $\mathrm{O}_{2}$ band for the determination of $\mathrm{XCO}_{2}$ and $\mathrm{XCH}_{4}$ scattering needs to be explicitly accounted for.

An alternative approach for the determination of $\mathrm{XCH}_{4}$ at least in regions where diurnal or spatial $\mathrm{CO}_{2}$ variations are small is to assume that the $\mathrm{CO}_{2}$ is effectively constant and well mixed compared to $\mathrm{CH}_{4}$. As the relevant relatively weak absorptions of both gases occur spectrally close to one another, the path of the electromagnetic radiation is similar for $\mathrm{CO}_{2}$ and $\mathrm{CH}_{4}$. For this reason, one of the $\mathrm{XCH}_{4}$ data products is retrieved from SCIAMACHY (Frankenberg et al., 2005; Schneising et al., 2009) in this way. For this approach to be valid for the scene, $\mathrm{CO}_{2}$ must be significantly less variable than $\mathrm{CH}_{4}$. For the SCIAMACHY's large ground pixel size $(30 \mathrm{~km} \times 60 \mathrm{~km})$ this is reasonable, but could be problematic for the much smaller MAMAP ground pixel size. In several circumstances also a vice versa approach can be applied where larger $\mathrm{CO}_{2}$ variability is expected with respect to $\mathrm{CH}_{4}$, e.g. for strong anthropogenic $\mathrm{CO}_{2}$ emitters (see Sect. 6).

In summary all three methods could be used for MAMAP. The method, which performs best, depends on the target and the validity of the assumptions and the effort made to account for cloud and aerosol within the retrieval algorithm.

In this manuscript we focus on results obtained in the SWIR $(1.6 \mu \mathrm{m})$ channel of MAMAP. To assess the instrument performance we have developed an initial version of a 
retrieval algorithm for MAMAP. In the following we present a short characterization of this algorithm. A more detailed description will be given elsewhere (Krings et al., 2011).

The MAMAP retrieval algorithm, used in this study, is derived from the Weighting Function Modified Differential Optical Absorption Spectroscopy (WFM-DOAS) retrieval algorithm (Buchwitz et al., 2000), referred to as the WFMD/M retrieval algorithm. The WFM-DOAS retrieval algorithm has been developed for and applied successfully to the retrieval of $\mathrm{CH}_{4}$ and $\mathrm{CO}_{2}$ vertical columns from SCIAMACHY nadir spectra (Buchwitz et al., 2005a,b; Schneising et al., 2008, 2009). Similar to WFM-DOAS, the WFMD/M retrieval algorithm uses a least-squares fitting procedure to minimise the difference between the logarithm of a simulated radiance spectrum with that measured. The simulated spectrum and the derivatives ("Jacobians") of this spectrum with respect to a change of atmospheric parameters are computed with the radiative transfer model (RTM) SCIATRAN (Rozanov et al., 2005) using the HITRAN data base (Rothman et al., 2005) and the solar spectrum from Livingston and Wallace (1991). These derivatives are called weighting functions. In addition to the geophysical fit parameters (i.e. $\mathrm{CO}_{2}, \mathrm{H}_{2} \mathrm{O}$, temperature for $\mathrm{CO}_{2}$ retrieval and $\mathrm{CH}_{4}, \mathrm{CO}_{2}, \mathrm{H}_{2} \mathrm{O}$, temperature for $\mathrm{CH}_{4}$ retrieval respectively), a low order polynomial in the spectral domain is used to account for all smoothly varying spectral parameters, which are not explicitly modelled or inadequately known. These parameters include, for example, the MAMAP absolute radiometric calibration function, aerosol scattering, absorption parameters and the surface spectral reflectance. Finally also an odd-even correction fitting an alternating function $(-1,1,-1,1, \ldots)$ is applied. The odd-even effect is caused by the multiplexer design of the SWIR detector in combination with the tilted illumination. For all retrievals a standard background aerosol scenario as in Schneising et al. (2008) is used and a constant albedo of 0.18 (Lambertian surface) was applied as first approximation, assuming that most biases introduced by these assumptions will be small in the resulting ratios.

The spectral calibration of the system was obtained by shifting and squeezing the measured spectra with repect to the RTM simulated spectrum while minimizing the residuum. Once the optimum spectral calibration parameter were obtained only shifting was performed in the future data processing. Slit function parameters were optimized in a similar way. The measured slit function was fitted by two Gaussina line shape functions. After that the FWHM was adjusted while minimizing the residuum for the $\mathrm{CO}_{2}$ and $\mathrm{CH}_{4}$ windows respectively. Once optimum slit function parameters were obtained, no further adjustment of the FWHM was applied to the subsequent processing of the data.

Figure 5 shows an example result for a WFMD/M analysis of a single spectrum, recorded by the MAMAP SWIR channel. The absorption features of $\mathrm{CH}_{4}$ (Fig. 5 left) and $\mathrm{CO}_{2}$ (Fig. 5 right) are clearly visible in the MAMAP spectrum. Interfering gases in the $\mathrm{CH}_{4}$ fitting window (left) are
$\mathrm{CO}_{2}$ and $\mathrm{H}_{2} \mathrm{O}$. In the $\mathrm{CO}_{2}$ fitting window (right) only $\mathrm{H}_{2} \mathrm{O}$ interferes. Also fitted is the shift of the temperature profile (only shown for the $\mathrm{CO}_{2}$ fitting window). The retrieved $\mathrm{CH}_{4}$ profile scaling factor (PSF) is $0.989 \pm 0.014$. The retrieved $\mathrm{CO}_{2} \mathrm{PSF}$ is $0.991 \pm 0.022$. The residual ("RES") is shown in the bottom panels and is the difference between the MAMAP spectral measurements and the fitted radiative transfer model. The root-mean-square (RMS) of the residual is $\sim 0.6 \%$ for both fitting windows. As can be seen, the fit residual is not only determined by measurement noise but also contains systematic features. This is currently attributed to wavelength calibration errors, slit function uncertainties, uncertainties of the spectroscopic line parameters or spectral structures of the white lamp calibration source.

As a result of the correlation between weighting functions of different altitude layers, the MAMAP retrieval is not height sensitive and weighting functions are integrated over the entire profile. Thus, the retrieval output PSF always indicates an altitude averaged change in the column concentration. For example a PSF of 1.01 means that the retrieved column is $1 \%$ higher than the vertical column which has been assumed for the radiative transfer simulations. During a flight of the MAMAP instrument, significant concentrations changes are expected below the aircraft, resulting from significant changes in surface emission fluxes. Inspection of the averaging kernels (i.e. the sensitivity of the retrieved parameter as a result of a perturbation of the true column) (Fig. 6) shows a striking difference of about a factor of two below and above the aircraft. This difference is explained by the fact that for a nadir viewing instrument electromagnetic radiation coming from the sun passes through the absorber below the aircraft twice: once before and once after surface reflection (or surface scattering). SCIATRAN accounts for the actual light path in the weighting functions for each layer. The current retrieval algorithm only uses the co-added weighting functions from all height layers. Hence a column averaged PSF will always overestimate the real concentrations in the total column, because the averaged weighting functions are smaller than the weighting functions below the aircraft. To account only for an increase or decrease in $\mathrm{CO}_{2}$ and $\mathrm{CH}_{4}$ concentrations compared to background below the aircraft while leaving the column above unchanged, the original profile scaling factors (PSF) is multiplied by a conversion factor $c$ (Table 2) derived from RTM simulations. The resulting new column scaling factor (CSF) as the scaling factor for the total column increase or decrease, assuming that all changes in concentrations of $\mathrm{CH}_{4}$ occur below the aircraft and the $\mathrm{CO}_{2}$ concentration is constant - can be calculated from:

$\mathrm{CSF}=1.0+(\mathrm{PSF}-1.0) \cdot c$

The conversion factor $c$ depends on geometry (aircraft altitude, solar zenith angle), atmospheric distribution of the according trace gas, and the surface albedo/SSR. 

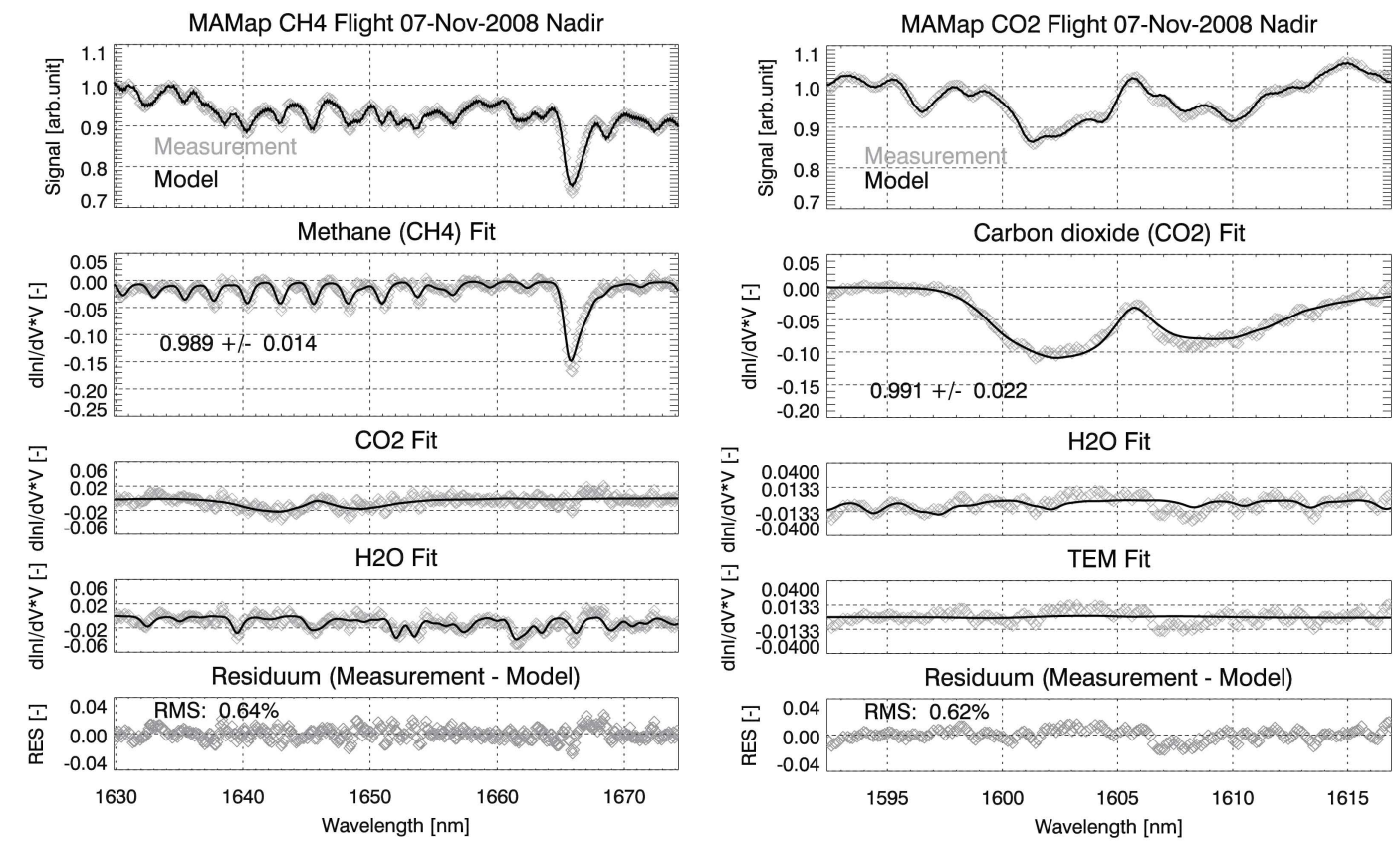

Fig. 5. WFM-DOAS fits in the spectral regions used for $\mathrm{CH}_{4}$ (left) and $\mathrm{CO}_{2}$ (right) retrieval. The MAMAP spectral measurements have been made on 7 November 2008 during the flight from Oshawa to Wilmington, USA, on board of the Polar-5 aircraft of the Alfred-WegenerInstitute (AWI), Bremerhaven, Germany. Left: The top panel shows a MAMAP nadir spectrum (grey symbols) and the solid line the fitted linearized radiative transfer model. The bottom panel shows the fit residuum, which is the difference between measurement and simulation after the fit (the root-mean-square, RMS, of the fit residuum, RES, is $0.64 \%$ ). The second panel shows details of the methane fit. The solid line is the scaled derivative of the radiance with respect to a change of the methane vertical column. The retrieved scaling factor for the methane vertical profile is $0.989 \pm 0.014$, i.e., the retrieved columns is $1.1 \%$ lower than the vertical column which has been assumed for the radiative transfer simulations. The grey symbols show the "methane fit residuum", which is identical with the black curve except that the spectral fit residuum has been added. The third and the fourth panel show the corresponding results for the interfering gases $\mathrm{CO}_{2}$ and $\mathrm{H}_{2} \mathrm{O}$. Right: similar as left figure but for the $\mathrm{CO}_{2}$ fitting window.

Assuming an average mixing ratio of $1774 \mathrm{ppb}$ for $\mathrm{CH}_{4}$, the concentration change in the total column below the aircraft $\Delta C$ is then estimated by the following equation:

$\Delta C_{\mathrm{ppb}}=(1774 \mathrm{ppb} \cdot \mathrm{CSF})-1774 \mathrm{ppb}$

A similar calculation can also be performed for $\mathrm{CO}_{2}$.

Currently the WFMD/M retrieval algorithm is modified to invert directly changes below the aircraft. MAMAP zenith sky data are used to compare to nadir data, to derive column changes and to validate the assumption of an unchanged column above the aircraft.

\section{Performance assessment of the SWIR channel}

The instrument performance of the SWIR channel of MAMAP has been evaluated in two different ways: (i) by estimation of the signal-to-noise ratio (SNR) for each measured spectrum (Sect. 4.1) and (ii) by estimation of the instrument precision (Sect. 4.2). Time series of single detector readout and co-added burst mode measurements obtained for different operation conditions (on ground and in-flight) are analysed and compared in Sect. 4.3. In Sect. 4.4 the spectral stability of the system is examined. The on-ground measurements were carried out in May 2006 on the campus of the University of Bremen. The in-flight measurements were performed onboard the AWI Polar-5 aircraft and the FU-Berlin Cessna 207 aircraft during campaigns in August 2007 and November 2008. In the following sections the terms precision, accuracy, relative accuracy and measurement uncertainty are used. These are defined as follows:

- Precision includes all random errors in the measurement and the retrieval resulting from detector shot noise, random illumination effects and other random effects. As systematic fast varying (near random) albedo/SSR effects can not be separated from the other fast random effects, they also are accounted for in the precision.

- Accuracy includes all systematic errors in the measurement and the retrieval resulting from aerosols and clouds, uncertainties resulting from insufficient knowledge of the slit function shape, errors resulting from the a priori profile and temperature information, the spectroscopic line parameters, SZA effects, the flight altitude and other systematic errors. 

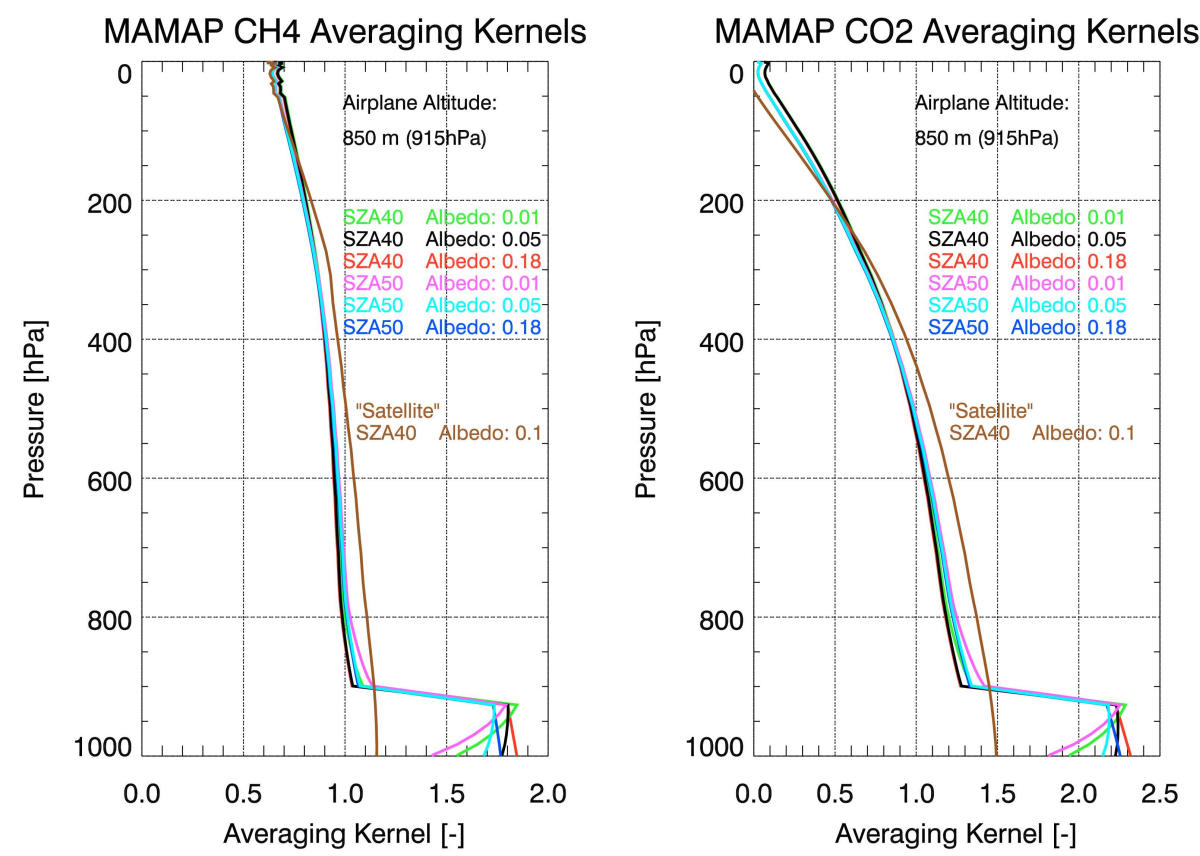

Fig. 6. Averaging kernels for the MAMAP instrument depending on solar zenith angle (SZA) and surface albedo/SSR for a nadir measurement at $850 \mathrm{~m}$ flight altitude. The figure shows the striking difference of the averaging kernels below the instrument compared to above the instrument. This difference is due to the fact that for a nadir viewing instrument light coming from the sun passes through the absorber below the aircraft twice (once before and once after reflection at the surface). Left: averaging kernels for $\mathrm{CH}_{4}$; right: averaging kernels for $\mathrm{CO}_{2}$.

Table 2. MAMAP total column conversion factors $c$ for retrieval output profile scaling factors (PSF), assuming all deviations from mean column occurred below the aircraft. All conversion factors were computed based on SCIATRAN RTM simulations.

\begin{tabular}{ccccc}
\hline $\begin{array}{c}\text { Airplane } \\
\text { altitude }\end{array}$ & $\begin{array}{c}\text { Solar } \\
\text { zenith } \\
\text { angle }\end{array}$ & $\begin{array}{c}\text { Surface } \\
\text { albedo }\end{array}$ & \multicolumn{2}{c}{ Conversion Factor $c$} \\
$\mathrm{CH}_{4}$ & $\mathrm{CO}_{2}$ \\
{$[\mathrm{~m}]$} & $\left.{ }^{\circ}\right]$ & {$[-]$} & {$[-]$} & {$[-]$} \\
\hline 850 & 40 & 0.01 & 0.575 & 0.459 \\
850 & 40 & 0.05 & 0.546 & 0.435 \\
850 & 40 & 0.18 & 0.535 & 0.426 \\
850 & 50 & 0.01 & 0.607 & 0.478 \\
850 & 50 & 0.05 & 0.571 & 0.448 \\
850 & 50 & 0.18 & 0.558 & 0.438 \\
1250 & 40 & 0.18 & 0.556 & 0.447 \\
4500 & 40 & 0.01 & 0.729 & 0.619 \\
4500 & 40 & 0.05 & 0.712 & 0.604 \\
4500 & 40 & 0.18 & 0.706 & 0.599 \\
4500 & 50 & 0.01 & 0.747 & 0.626 \\
4500 & 50 & 0.05 & 0.727 & 0.609 \\
4500 & 50 & 0.18 & 0.720 & 0.603 \\
\hline
\end{tabular}

- Relative accuracy (accuracy variation) includes all systematic error variations in the measurement excluding constant systematic biases caused for instance by insufficient knowledge of the slit function shape, etc.
- Measurement uncertainty is defined as the sum of both, systematic and random errors.

\subsection{Signal to noise ratios (SNRs)}

The SNR of MAMAP determines (in combination with spectral resolution and spectral sampling) to a large degree the achievable precisions with these type of spectrometers. The SNR for the SWIR band of MAMAP was evaluated in two different ways: (i) by an estimate via simulations (Sect. 4.1.1) and (ii) by a SNR estimate from real measurements (Sect. 4.1.2). Results for both estimates are later compared and discussed in Sect. 4.3 for different operation conditions.

\subsubsection{SNR computations based on simulations}

A theoretical noise $(N)$ estimate for single detector readouts of the MAMAP system was inferred by applying the MAMAP instrument model simulation to a radiative transfer model spectrum. The noise for each detector pixel was calculated from the resulting shot noise of the estimated detector signal, the shot noise of the detector dark signal, the readout noise of the detector and the analog to digital converter. The simulated SNR for each detector pixel - SNR(sim) - was calculated by dividing the calculated detector signal $(S)$ by the calculated noise $(N)$.

$\operatorname{SNR}(\operatorname{sim})=S / N$ 
Table 3. Simulated and measured MAMAP SWIR single readout detector performance for different reference targets including on-ground and in-flight measurements. The table includes the exposure time $t_{\text {exp }}$ (column 3), the simulated and measured signal in [BU] (column 4 and 5), the simulated and retrieved SNR (column 6 and 7), the simulated profile scaling factor precision (PSFP) for each gas (column 8) and the simulated and (from measurements) mean retrieved profile scaling factor ratio precision (PSFRP) calculated from the $\mathrm{CH}_{4} / \mathrm{CO}_{2} \mathrm{PSF}$ ratios (column 9 and 10).

\begin{tabular}{|c|c|c|c|c|c|c|c|c|c|}
\hline Target & Gas & $\begin{array}{l}t_{\exp } \\
{[\mathrm{s}]}\end{array}$ & $\begin{array}{r}\text { Signal } \\
(\text { sim) } \\
{[\mathrm{BU}]}\end{array}$ & $\begin{array}{c}\overline{\text { Signal }} \\
\text { (meas) } \\
{[\mathrm{BU}]}\end{array}$ & $\begin{array}{l}\overline{\text { SNR }} \\
(\mathrm{sim}) \\
{[-]}\end{array}$ & $\begin{array}{l}\overline{\text { SNR }} \\
\text { (ret) } \\
{[-]}\end{array}$ & $\begin{array}{c}\text { PSFP } \\
\text { (sim) } \\
{[\%]}\end{array}$ & $\begin{array}{c}\text { PSFRP } \\
\text { (sim) } \\
{[\%]}\end{array}$ & $\begin{array}{c}\text { PSFRP } \\
\text { (ret) } \\
{[\%]}\end{array}$ \\
\hline WHO & $\mathrm{CO}_{2}$ & 1.000 & 9230 & \multirow{2}{*}{12158} & 542 & 411 & 0.69 & \multirow{2}{*}{0.83} & \multirow[b]{2}{*}{1.12} \\
\hline WHO & $\mathrm{CH}_{4}$ & 1.000 & 9130 & & 533 & 422 & 0.47 & & \\
\hline WIH & $\mathrm{CO}_{2}$ & 1.000 & 24000 & \multirow{2}{*}{26612} & 1063 & 598 & 0.35 & \multirow{2}{*}{0.42} & \multirow{2}{*}{2.74} \\
\hline WIH & $\mathrm{CH}_{4}$ & 1.000 & 23435 & & 1047 & 532 & 0.24 & & \\
\hline LHO & $\mathrm{CO}_{2}$ & 0.058 & 9636 & \multirow{2}{*}{11480} & 638 & 588 & 0.59 & \multirow{2}{*}{0.71} & \multirow{2}{*}{1.10} \\
\hline LHO & $\mathrm{CH}_{4}$ & 0.058 & 9410 & & 628 & 538 & 0.39 & & \\
\hline LIH & $\mathrm{CO}_{2}$ & 0.058 & 9636 & \multirow{2}{*}{11618} & 638 & 475 & 0.59 & \multirow{2}{*}{0.71} & \multirow{2}{*}{2.80} \\
\hline LIH & $\mathrm{CH}_{4}$ & 0.058 & 9410 & & 628 & 418 & 0.39 & & \\
\hline ZIR & $\mathrm{CO}_{2}$ & 0.400 & 9969 & \multirow{2}{*}{10814} & 621 & 620 & 0.60 & \multirow{2}{*}{0.72} & \multirow{2}{*}{0.59} \\
\hline ZIR & $\mathrm{CH}_{4}$ & 0.400 & 9734 & & 611 & 570 & 0.41 & & \\
\hline ZRG & $\mathrm{CO}_{2}$ & 0.700 & 33600 & \multirow{2}{*}{333} & 1338 & 1290 & 0.28 & \multirow{2}{*}{0.33} & \multirow{2}{*}{0.63} \\
\hline ZRG & $\mathrm{CH}_{4}$ & 0.700 & 32890 & & 1319 & 1181 & 0.19 & & \\
\hline SIT & $\mathrm{CO}_{2}$ & 0.148 & 43716 & \multirow{2}{*}{45614} & 1605 & 1651 & 0.23 & \multirow{2}{*}{0.27} & \multirow{2}{*}{0.33} \\
\hline SIT & $\mathrm{CH}_{4}$ & 0.148 & 42000 & & 1584 & 1566 & 0.15 & & \\
\hline
\end{tabular}

To simulate the functioning of MAMAP, a model was developed, based on the CarbonSat instrument model (Bovensmann et al., 2010), which is similar in concept to that used for SCIAMACHY. For comparison, simulated signals (in [BU]) and simulated SNR values - SNR(sim) - for different operation conditions are averaged over all detector pixels of the entire fitting windows of $\mathrm{CH}_{4}$ and $\mathrm{CO}_{2}$, and summarized in Table 3. In nominal operation, the MAMAP instrument utilises the so called "co-added burst mode". In this mode the instrument acquires a burst of a programmable number of $n$ single spectra (typically $n=10$ ). All acquired spectra of each burst are co-added during subsequent processing (Sect. 2). Assuming a Gaussian error distribution for the single detector readouts, the simulated co-added burst mode (BM) signal-tonoise ratio - $\mathrm{SNR}_{\mathrm{BM}}(\mathrm{sim})$ - of each co-added measurement was calculated from the simulated single readout SNR(sim) by:

$\operatorname{SNR}_{\mathrm{BM}}(\operatorname{sim})=\operatorname{SNR}(\operatorname{sim}) \cdot \sqrt{n}$

\subsubsection{SNR estimates from real data}

For comparison with the modelled values, the SNR of MAMAP was estimated from real data. The SNR has been calculated from the individual fit residuum ("RES ${ }_{i}$ ", see Sect. 3) of each single measurement for the two fit-windows used for $\mathrm{CH}_{4}$ and $\mathrm{CO}_{2}$. As RES $\mathrm{R}_{i}$ of each $i$-th measurement contains systematic features, the mean residuum for all measured spectra of the processed data set has been calculated
Table 4. MAMAP in-flight SWIR detector performance over inhomogeneous land targets (LIH) for co-added burst mode. The table include the simulated and retrieved SNR of the instrument for $10 \mathrm{co-}$ added burs mode (BM) measurements (column 4 and 5) and also the simulated and (from measurements) retrieved $\mathrm{CH}_{4} / \mathrm{CO}_{2} \mathrm{PSF}$ ratio precision $\left(\mathrm{PSFRP}_{\mathrm{BM}}\right)$ in column 6 and 7.

\begin{tabular}{lcccccc}
\hline Target & Gas & $t_{\text {int }}$ & $\begin{array}{c}\overline{\mathrm{SNR}}_{\mathrm{BM}} \\
(\mathrm{sim})\end{array}$ & $\begin{array}{c}\overline{\mathrm{SNR}}_{\mathrm{BM}} \\
(\mathrm{ret})\end{array}$ & $\begin{array}{c}\mathrm{PSFRP}_{\mathrm{BM}} \\
(\mathrm{sim}) \\
{[\%]}\end{array}$ & $\begin{array}{c}\mathrm{PSFRP}_{\mathrm{BM}} \\
(\mathrm{ret}) \\
{[\%]}\end{array}$ \\
\hline LIH & $\mathrm{CO}_{2}$ & 0.58 & 2017 & 957 & 0.225 & 1.74 \\
LIH & $\mathrm{CH}_{4}$ & 0.58 & 1986 & 827 & & \\
\hline
\end{tabular}

and subtracted from the individual RES $i$ spectra to remove the systematic components contained in $\mathrm{RES}_{i}$ :

$\mathrm{RES}_{i}{ }^{\prime}=\mathrm{RES}_{i}-\overline{\operatorname{RES}}_{1 \ldots n}$

After subtraction $\mathrm{RES}_{i}{ }^{\prime}$ contains shot noise, detector noise, noise effects resulting from varying spectral structures of the measured (spectral) radiance, noise effects due to tilted illumination of the detector and noise effects resulting from inhomogeneous illumination. The latter result from changes of the instrument slit function, induced by keystone and smile effects of the optical system of the MAMAP spectrometer in combination with inhomogeneous illumination of the slit. Even-odd effects are induced by tilted illumination of the linear $\mathrm{InGaAs}$ detector due to the multiplexer design. 
To estimate the SNR of each measurement, first the standard deviation (SRES) of the resulting new fit residuals $\left(\mathrm{RES}_{i}{ }^{\prime}\right)$ has been retrieved for each single spectra:

$\operatorname{SRES}_{i}=\operatorname{SDEV}\left(\operatorname{RES}_{i}^{\prime}\right)$

The SNR of each measurement was then estimated by the reciprocal value of the standard deviation:

$\mathrm{SNR}(\mathrm{ret})_{i}=1 / \mathrm{SRES}_{i}$

For comparison with the simulated values, also the mean SNR values $\overline{\mathrm{SNR}}(\mathrm{ret})_{1 \ldots n}$ and mean measured signal values $\bar{S}$ (meas) were calculated for a selected set of measurement sequences and summarized in Table 3 (see Sect. 4.3). For co-added burst-mode (see Sect. 4.1.1) the retrieved SNR $\mathrm{SNR}_{\mathrm{BM}}$ (ret) - has been estimated in a similar way as for the single detector readouts but using the burst averaged residua. The results are summarized in Table 4.

\section{2 $\mathrm{CO}_{2}$ and $\mathrm{CH}_{4}$ retrieval precisions}

The instrument precision which can be reached by a grating spectrometer system can be theoretically evaluated as performed in Sect. 4.2.1 or retrieved from real data sets as performed in Sect. 4.2.2. Results for both estimates are compared for different operation conditions in Sect. 4.3.

\subsubsection{Theoretical retrieval precisions}

The theoretical retrieval precision of MAMAP for $\mathrm{CH}_{4}$ and $\mathrm{CO}_{2}$ was estimated from the corresponding simulated SNR (Sect. 4.1.1) and from the instruments spectral resolution and spectral sampling. The solution of the WFMD/M algorithm is based on a least squares approach of the following form:

$\boldsymbol{y}=\mathbf{K} \cdot \boldsymbol{x}+\boldsymbol{\epsilon}$

where $\mathbf{K}$ denotes the weighting function matrix, $\boldsymbol{y}$ denotes the wavelength dependent difference between measurements and model, and $\boldsymbol{x}$ the parameters to be retrieved. The error is expressed by $\boldsymbol{\epsilon}$. With the inverse measurement covariance matrix $\mathbf{C}_{y}^{-1}$ derived for the simulated SNR the weighted least squares solution can be written as:

$\boldsymbol{x}=\left(\mathbf{K}^{t} \mathbf{C}_{y}^{-1} \mathbf{K}\right)^{-1} \mathbf{K}^{t} \mathbf{C}_{y}^{-1} \boldsymbol{y}$

with the corresponding parameter covariance matrix:

$\mathbf{C}_{x}=\left(\mathbf{K}^{t} \mathbf{C}_{y}^{-1} \mathbf{K}\right)^{-1}$

The diagonals give the variance of the parameters. Hence the simulated profile scaling factor precision PSFP can be calculated (for $1 \sigma$ ) as:

$\operatorname{PSFP}(\operatorname{sim})_{\mathrm{CH}_{4}}=\sqrt{C_{x}, \mathrm{CH}_{4}}$ for $\mathrm{CH}_{4}$

and

$\operatorname{PSFP}(\operatorname{sim})_{\mathrm{CO}_{2}}=\sqrt{C_{x, \mathrm{CO}_{2}}}$ for $\mathrm{CO}_{2}$.
Results for the individual PSFP(sim) calculated for different instrument operation conditions are summarized in Table 3. Accordingly, the simulated precision for the profile scaling factor ratios PSFRP(sim) can be calculated from the Gaussian error propagation and the individual simulated PSF precisions - $\mathrm{PSFP}_{\mathrm{CH}_{4}}(\mathrm{sim})$ and $\mathrm{PSFP}_{\mathrm{CO}_{2}}(\operatorname{sim})$ - of each gas:

$\operatorname{PSFRP}(\operatorname{sim})=$

$=\sqrt{\frac{\left(\mathrm{PSFP}_{\mathrm{CH}_{4}}(\operatorname{sim})\right)^{2}}{\left(\mathrm{PSFP}_{\text {ref }, \mathrm{CO}_{2}}(\operatorname{sim})\right)^{2}}+\frac{\left(\mathrm{PSFP}_{\mathrm{CO}_{2}}(\operatorname{sim})\right)^{2} \cdot\left(\mathrm{PSFP}_{\mathrm{ref}, \mathrm{CH}_{4}}(\operatorname{sim})\right)^{2}}{\left(\mathrm{PSFP}_{\text {ref }, \mathrm{CO}_{2}}(\operatorname{sim})\right)^{4}}}$

Since the reference columns are normalized to background concentration - i.e. $\operatorname{PSFP}_{\text {ref, }, \mathrm{CO}_{2}}(\operatorname{sim})=1, \operatorname{PSFP}_{\text {ref }, \mathrm{CH}_{4}}(\operatorname{sim})$ $=1-$ it follows:

$\operatorname{PSFRP}(\operatorname{sim})=\sqrt{\operatorname{PSFP}_{\mathrm{CH}_{4}}(\operatorname{sim})^{2}+\operatorname{PSFP}_{\mathrm{CO}_{2}}(\operatorname{sim})^{2}}$

Assuming a Gaussian error distribution for the single measurements obtained by MAMAP, the simulated co-added burst mode (BM) PSFR precision - $\operatorname{PSFRP}_{\mathrm{BM}}(\mathrm{sim})-$ of each co-added measurement can be calculated from the simulated single readout PSFR precisions - PSFRP(sim) - and the number of co-added measurements as:

$\operatorname{PSFRP}_{\mathrm{BM}}(\operatorname{sim})=\operatorname{PSFRP}(\operatorname{sim}) / \sqrt{n}$

\subsubsection{Precision estimates obtained using real data}

To estimate the instrument precision for a given data set, the individual $\mathrm{CH}_{4}$ and $\mathrm{CO}_{2}$ columns were processed for each single measured spectra with the WFMD/M retrieval algorithm as described in Sect. 3. To account for small systematic offsets caused for instance by insufficient knowledge of the slit function used for the fit procedure, each series of profile scaling factors $\left(\mathrm{PSF}_{i}\right)$ was first normalized for each gas by the mean value of all measurements of the processed data set. The resulting normalized profile scaling factors NPSF $_{i}$ can be calculated as:

$\mathrm{NPSF}_{i}=\mathrm{PSF}_{i} / \overline{\mathrm{PSF}}_{1 \ldots n}$

To account for path differences caused by topography and movements of the plane the (normalized) $\mathrm{CH}_{4} / \mathrm{CO}_{2}$ profile scaling factor ratio $\left(\mathrm{PSFR}_{i}\right)$ was calculated as discussed in Sect. 3:

$\operatorname{PSFR}\left(\mathrm{CH}_{4} / \mathrm{CO}_{2}\right)_{i}=\operatorname{NPSF}\left(\mathrm{CH}_{4}\right)_{i} / \operatorname{NPSF}\left(\mathrm{CO}_{2}\right)_{i}$

To account for slow SZA and atmospheric variations the $\mathrm{CH}_{4} / \mathrm{CO}_{2}$ PSFR were additionally high-pass filtered. The retrieved profile scaling factor ratio precision PSFRP(ret) was then calculated as standard deviation of the $\mathrm{PSFR}_{i}$ over the whole investigated data set:

$\operatorname{PSFRP}($ ret $)=\operatorname{SDEV}\left(\operatorname{PSFR}\left(\mathrm{CH}_{4} / \mathrm{CO}_{2}\right)_{1 \ldots n}\right)$

This procedure was repeated for a set of measurement sequences for different operation conditions of the instrument 
Table 5. MAMAP reference targets data set selected for precision estimates.

\begin{tabular}{|c|c|c|c|c|}
\hline Abbreviation & Target & $\begin{array}{l}\text { Observation } \\
\text { conditions }\end{array}$ & $\begin{array}{l}\text { Illumination } \\
\text { of slit }\end{array}$ & $\begin{array}{l}\text { Observation } \\
\text { geometry }\end{array}$ \\
\hline WHO & water radiance & dynamic (in-flight) & homogeneous, slight dynamic changes & nadir \\
\hline WIH & water radiance & dynamic (in-flight) & inhomogeneous, dynamic changes & nadir \\
\hline LHO & land radiance & dynamic (in-flight) & inhomogeneous, slight dynamic changes & nadir \\
\hline LIH & land radiance & dynamic (in-flight) & inhomogeneous, dynamic changes & nadir \\
\hline ZIR & $\begin{array}{l}\text { solar }+ \text { hemispheric } \\
\text { radiance and irradiance }\end{array}$ & dynamic (in-flight) & homogeneous, changes only in intensity & $\begin{array}{l}\text { zenith (over } 3 \\
\text { transmissive } \\
\text { diffusers + fiber) }\end{array}$ \\
\hline ZRG & zenith radiance & static (on-ground) & $\begin{array}{l}\text { homogeneous, slight variations } \\
\text { in aerosols and clouds }\end{array}$ & zenith \\
\hline SIT & $\begin{array}{l}\text { sun illuminated } \\
\text { target, radiance }\end{array}$ & static (on-ground) & inhomogeneous, static no changes & SIT (quasi nadir) \\
\hline
\end{tabular}

as described in the next section. The obtained results from these sequences are summarized in Table 3 and compared to simulated values (see Sect. 4.2.1). For co-added burst-mode (see Sect. 4.1.1) the retrieved profile scaling factor ratio precision PSFRP $\mathrm{BM}_{\mathrm{BM}}(\mathrm{ret})$ has been estimated in a similar way as for the single detector readouts, but using the burst averaged profile scaling factors PSF $_{\mathrm{BM}}$ instead. Results for co-added burst mode obtained from one data set are summarized in Table 4.

\subsection{Single exposure SNR and precision for different operation conditions}

To estimate the SNR and the PSFR precision (PSFRP) of the MAMAP instrument under different operating conditions, a data set of seven measurement sequences has been selected, including static on-ground and dynamic in-flight measurements. The in-flight sequences have been subdivided into measurement sequences over surfaces containing primarily homogeneous and surfaces containing primarily inhomogeneous distribution of the measured radiance (see Table 5). These sequences produce primarily homogeneous and variable inhomogeneous illumination conditions on the spectrometers slit, respectively. In addition, sequences of zenith sky in-flight measurements were investigated for which the slit was illuminated uniformly. In the following results obtained for the different operation conditions will be presented and discussed. For all sequences $\mathrm{CH}_{4}$ and $\mathrm{CO}_{2} \overline{\mathrm{SNR}}$ values, profile scaling factors (PSF) and associated PSFR precisions have been retrieved for single detector readouts as described in Sect. 4.2. For comparison also the associated simulated $\overline{\mathrm{SNR}}$ values and PSFR precisions were computed as described in Sects. 4.1 and 4.2. All results of these calculations are summarized in Table 3. By intercomparison of the different results, potential error sources affecting the instrument performance can be identified or excluded.

\subsubsection{Ground based measurements}

To investigate the instrument's performance under vibrationfree static conditions, two types of on-ground measurements have been performed. In a first set-up the nadir telescopes of the spectrometer have been pointed towards a group of trees. This configuration is referred to as "pseudo" nadir or "sun-illuminated target" (SIT) configuration. The trees were located on the campus of the University of Bremen, in approximately $250 \mathrm{~m}$ distance to the MAMAP spectrometer. In this configuration a measurement sequence was acquired with a single readout exposure time of $148 \mathrm{~ms}$ at $\sim 70 \%$ detector saturation. The illumination conditions (signal levels) were nearly constant due to (nearly) clear sky conditions, in contrast to typical in-flight conditions, where the signal varies as a result of changes in the surface albedo/SSR.

In a second on-ground set-up, scattered light zenith radiance measurements (measurements of the down-welling diffuse radiance) were performed by pointing the MAMAP zenith telescopes directly into the sky. The data were analyzed using a LOWTRAN aerosol background scenario for the RTM simulation delivering good results for the SNR and precision estimates with the described approach (see Sect. 4.2.2). The single readout exposure time for the acquired sequence was $700 \mathrm{~ms}$ at $\sim 56 \%$ detector saturation and clear sky conditions.

The measurements have not been absolutely calibrated but have been corrected for dead and bad pixels and dark signal. The spectra were also normalized using a white light source (WLS) spectrum to account for pixel to pixel gain variations and etalons. The spectrometers were temperature stabilized being heated to $\sim 26^{\circ} \mathrm{C}$ for an outside temperature of $\sim 15-20^{\circ} \mathrm{C}$.

After processing of both measurement sequences a RMS of the fit residuum (Sect. 3) in the range of $0.5-0.6 \%$ was 
achieved (i.e. very similar to the RMS obtained for well filtered in-fight measurements, see Fig. 5).

Figure 8 shows precision and RMS results obtained for the on-ground sequences after processing. On the left, the results from the sun illuminated target (SIT) measurements performed on 11 May 2006 are displayed. On the right, the results from ground-based scattered zenith radiance measurements performed on 10 May 2006 are shown. The top panel shows the normalized PSFR precisions for $\mathrm{CH}_{4} / \mathrm{CO}_{2}$. The second panel shows the measured signal in [BU] (for 16 Bit ADC) with dark signal subtracted. The bottom panel shows the SNR estimate of each measurement for each gas $\left(\mathrm{CH}_{4}\right.$ black, $\mathrm{CO}_{2}$ red symbols) as described in Sect. 4.1.2.

It is assumed that the precision and the SNR of the MAMAP instrument under static conditions on ground is primarily dominated by the shot noise of the measured signal, the dark signal shot noise and readout noise of the detector and front-end electronics. Vibrations or changes in the illumination conditions of the spectrometers can be omitted. Therefore good agreement between measurements and model simulations is expected.

For the SIT measurements (as expected) a very good agreement between simulated and retrieved SNR values can be achieved for single detector readouts. The simulated $\overline{\mathrm{SNR}}$ (sim) values for $\mathrm{CH}_{4}$ and $\mathrm{CO}_{2}$ are 1584 and 1605 vs. the retrieved $\overline{\mathrm{SNR}}$ (ret) values of 1566 and 1651 . The respective $\mathrm{CH}_{4} / \mathrm{CO}_{2}$ simulated vs. retrieved PSFR precision for $148 \mathrm{~ms}$ exposure time was $0.27 \%$ - PSFRP(sim) - vs. $0.33 \%$ - PSFRP(ret). Thus also for the precision, good agreement between model simulations and measurements can be obtained (Table 3).

For the scattered zenith sky radiance measurements, the mean SNR is in good agreement $(\overline{\mathrm{SNR}}(\operatorname{sim})=1319$ vs. $\overline{\mathrm{SNR}}(\mathrm{ret})=1181$ for $\mathrm{CH}_{4}$ and $\overline{\mathrm{SNR}}(\operatorname{sim})=1338$ vs. $\overline{\mathrm{SNR}}($ ret $)=1290$, respectively for $\mathrm{CO}_{2}$ ). In contrast, the simulated and retrieved $\mathrm{CH}_{4} / \mathrm{CO}_{2}$ PSFR precisions deviate by a factor of two $(0.33 \%$ - PSFRP(sim) - vs. $0.63 \%$ PSFRP(ret), for $700 \mathrm{~ms}$ exposure time). The origin of this difference is not yet identified. It may possibly be induced by atmospheric variations caused by turbulences and light path differences caused by aerosol scattering inside the measured air masses. Another possibility is absorption of liquid water or ice in aerosol and cirrus clouds, which results in a broad band absorption at the short wavelength end of the channel but is not explicitly accounted for in the retrieval. In general measurements in scattered zenith sky radiance geometry are likely to be more affected by atmospheric variations than measurements in SIT ("pseudo" nadir) geometry where the solar radiation is scattered/reflected primarily by the target opposed to the atmosphere.

Figure 7 shows a time series of SIT measurements under slightly variable atmospheric conditions. On the left results from single readout processing are shown. The top panel shows PSFs obtained for both gases $\left(\mathrm{CH}_{4}\right.$ black, $\mathrm{CO}_{2}$ red symbols). The second panel shows the $\mathrm{CH}_{4} / \mathrm{CO}_{2}$ PSFR. The bottom panel shows the measured signal in [BU] with dark signal subtracted. On the right, in analogy to the nominal in-flight burst mode (Sect. 4.3.4) results for the same time series with 10 co-added readouts are displayed. For the latter, the simulated burst mode PSFR precision - PSFRP $_{\mathrm{BM}}(\operatorname{sim})$ - can be calculated from the single readout precision as (see Sect. 4.2.1):

$\operatorname{PSFRP}_{\mathrm{BM}}(\operatorname{sim})=0.27 / \sqrt{10}=0.0854 \%$

Comparison with the second panel on the right shows reasonable agreement of the PSFRP $_{\mathrm{BM}}(\mathrm{sim})$ with the measured values. The systematic impact of atmospheric variability on the $\mathrm{CH}_{4}$ and $\mathrm{CO}_{2} \mathrm{PSF}$ accuracy variation is attributed to thin clouds. This exceeds the precision of the single measured values. Improving the retrieval to identify and account explicitly for thin cloud effects will further improve the accuracy of the retrieval.

\subsubsection{Airborne single readout measurements over homogeneous scenes}

To investigate the instrument performance under airborne conditions, the spectrometer rack (containing the SWIR and NIR spectrometer systems) was attached with 6 antivibration mounts to an aluminium aperture plate. This aperture plate contains two $10 \mathrm{~mm}$ thick wedged Suprasil aperture windows with a diameter of $180 \mathrm{~mm}$. The aperture plate itself was directly attached with screws to the structure of the plane (Fig. 4). Apart from vibrations, etalons from the Suprasil aperture windows and the spectrometer itself, spectral shifts caused by thermal gradients inside the spectrometers optical bench and effects from inhomogeneous slit illumination influence the in-flight measurements. To separate instrumental and vibration effects from illumination effects, first nadir measurement sequences over water and land with nearly homogeneous distribution of the measured radiance were investigated. It is thereby assumed that measurement sequences with smaller variations of the measured radiance (i.e. detector filling) will produce more homogeneous slit illumination conditions than measurement sequences where strong variations occur. To avoid detector saturation during airborne operation, the detector is operated in nadir mode typically at $\sim 10-20 \%$ of the total full well capacity $(\sim 6000$ $13000[\mathrm{BU}]$ at 16 bit resolution) corresponding to surface albedo/SSR over land in the range between $0.10-0.20$. The exposure time of each readout for these albedos/SSRs over land was typically in the range of $60-100 \mathrm{~ms}$, depending on solar zenith angle. Respectively over water (with typical albedos/SSRs of $\sim 0.01$ ) exposure times in the range between $0.6 \mathrm{~s}$ and $1 \mathrm{~s}$ were applied.

In Figs. 9 and 10 same plots as for ground based measurements (Fig. 8) are shown, but for dynamic in-flight conditions in nadir observation mode. The nadir measurement series over water are taken over the Caribbean Sea (9 Novomber 2008). The nadir measurement series over land 
MAMAP sun illuminated target (SIT) measurements (coadding $=1$ )

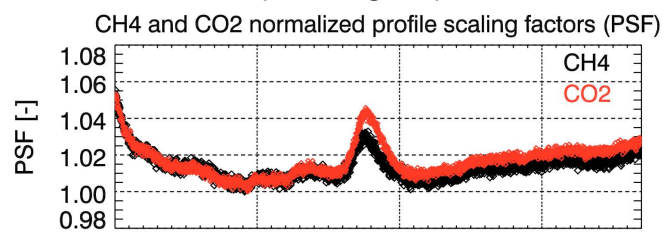

$\mathrm{CH} 4 / \mathrm{CO} 2$ normalized profile scaling factor ratios (PSFR)

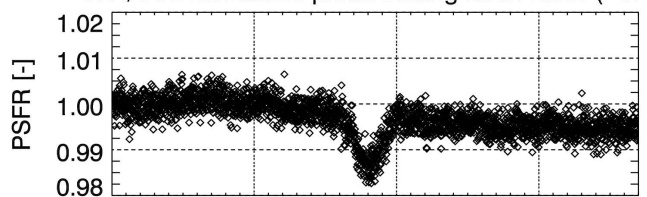

Detector filling

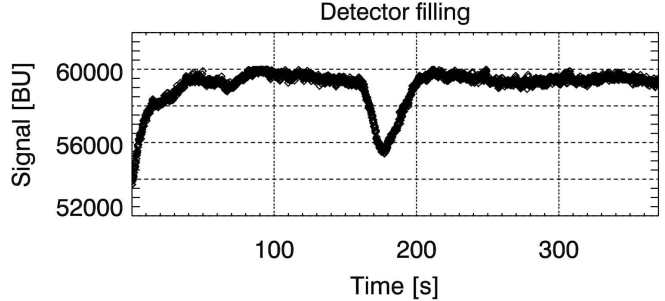

MAMAP sun illuminated target (SIT) measurements (coadding $=10$ )

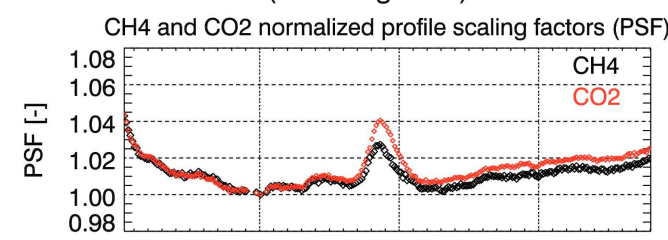

$\mathrm{CH} 4 / \mathrm{CO} 2$ normalized profile scaling factor ratios (PSFR)

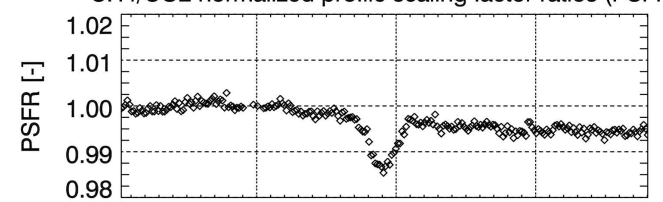

Detector filling

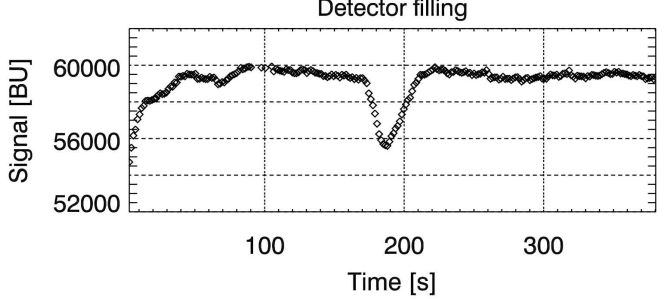

Fig. 7. Analysis of time series of MAMAP single detector readout $\mathrm{CH}_{4}$ and $\mathrm{CO}_{2}$ measurements (Left: for the $11 \mathrm{May} 2006$, Bremen stationary "on-ground" sun illuminated target, SIT, measurements, right: for the 10 May 2006 "on-ground" zenith sky scattered radiance, $\mathrm{ZRG}$, measurements). Left: top panel: normalized $\mathrm{CO}_{2} / \mathrm{CH}_{4}$ profile scaling factor ratios (PSFR ${ }_{i}$ ). Second panel: maximum radiance (detector filling) in binary units [BU] as measured with MAMAP and digitalized with 16 Bit ADC. Bottom panel: estimated signal-to-noise ratios (SNR) of the single measurements. Right: as on left side but for the zenith sky scattered radiance measurements (only measurements with $>3000[\mathrm{BU}]$ are processed).

are taken within the United States (7 November 2008). Both measurements are performed on board the AWI Polar-5 aircraft. On the left side of both figures (Figs. 9 and 10) measurement sequences for homogeneous and on the right side measurement sequences for inhomogeneous surface radiance distributions are presented.

Beside nadir measurements also airborne zenith irradiance measurement sequences were investigated. For this the instrument observes the upper hemispheric downwelling radiance and solar irradiance through a set of 4 transmissive Spectralon diffuser plates. The incoming radiation is fed from the diffusers to the instrument via glass fibers. Two lenses are imaging the fibers via the zenith optical path (Fig. 1) directly onto the slit of the spectrometer. In this mode of operation, the slit is always homogeneously illuminated and no additional spectral structures (as for instance due to features in the SSR) exist.

On the left, Fig. 11 shows measurement sequences taken by the zenith optical path of the instrument. The measurement is performed on board of a Cessna-207 aircraft. The readout to readout variation of the measured irradiance is very similar to that observed on ground (i.e. SIT measurements, Fig. 8).

The airborne zenith irradiance measurements (ZIR) show good agreement between simulated and retrieved SNR values $\left(\overline{\mathrm{SNR}}(\operatorname{sim})=611\right.$ vs. $\overline{\mathrm{SNR}}($ ret $)=570$ for $\mathrm{CH}_{4}$ and $\overline{\mathrm{SNR}}(\mathrm{sim})=621$ vs. $\overline{\mathrm{SNR}}($ ret $)=620$, respectively for $\left.\mathrm{CO}_{2}\right)$. The according simulated vs. retrieved PSFR precisions for single detector readouts and $400 \mathrm{~ms}$ exposure time were $0.72 \%$ (simulated) vs. $0.59 \%$ (retrieved).

For homogeneous radiance over water (WHO) also reasonable agreement between simulated and retrieved SNR and precisions are achieved $(\overline{\mathrm{SNR}}(\operatorname{sim})=533$ vs. $\overline{\mathrm{SNR}}($ ret $)=422$ for $\mathrm{CH}_{4}$ and $\overline{\mathrm{SNR}}(\mathrm{sim})=542\left(\mathrm{CO}_{2}\right)$ vs. $\overline{\mathrm{SNR}}($ meas $)=411$ for $\mathrm{CO}_{2}$ ). For single detector readouts and $1 \mathrm{~s}$ exposure time the respective simulated vs. retrieved PSFR precisions were $0.83 \%$ (simulated) vs. $1.12 \%$ (retrieved).

Over land targets with homogeneous upwelling radiance (LHO) the simulated vs. measured SNR were also in good agreement $\left(\overline{\mathrm{SNR}}(\mathrm{sim})=628\left(\mathrm{CH}_{4}\right)\right.$ vs. $\overline{\mathrm{SNR}}($ ret $)=538$ for $\mathrm{CH}_{4}$ and $\overline{\mathrm{SNR}}(\mathrm{sim})=638$ vs. $\overline{\mathrm{SNR}}(\mathrm{ret})=588$ for $\left.\mathrm{CO}_{2}\right)$. The respective simulated vs. retrieved PSFR precisions for single detector readouts and $58 \mathrm{~ms}$ exposure time were $0.71 \%$ (simulated) vs. $1.10 \%$ (retrieved) and agree also reasonably.

From these results it can be concluded that the in-flight measurements were barely affected by vibration effects or fast changing etalons. Assuming concentration changes to only occur in the $\mathrm{CH}_{4}$ column below the aircraft and the $\mathrm{CO}_{2}$ column as constant, the total column precision for $\mathrm{CH}_{4}-$ 
MAMAP Bremen, 11-May-2006 (SIT)

$\mathrm{CH} 4 / \mathrm{CO} 2$ normalized profile scaling factor ratio (PSFR)
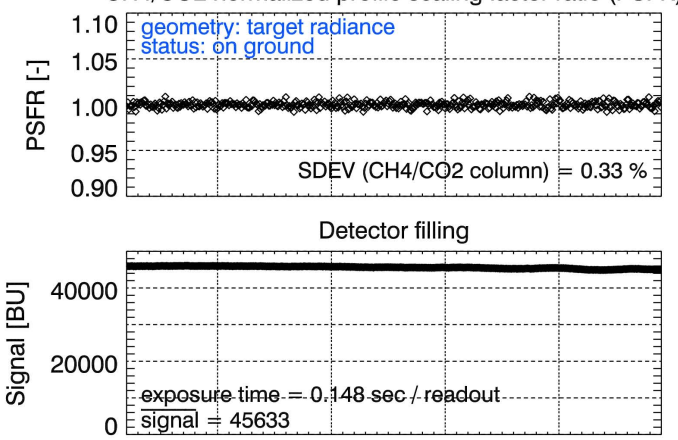

Signal to noise ratio

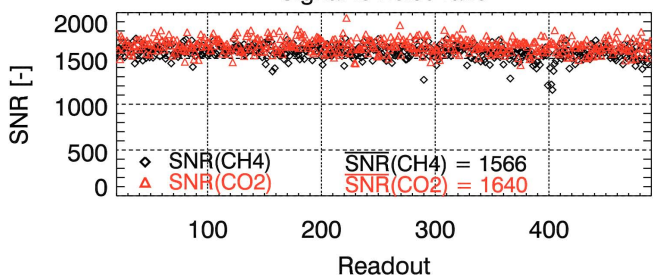

MAMAP Bremen, 10-May-2006 (ZRG)

$\mathrm{CH} 4 / \mathrm{CO} 2$ normalized profile scaling factor ratio (PSFR)
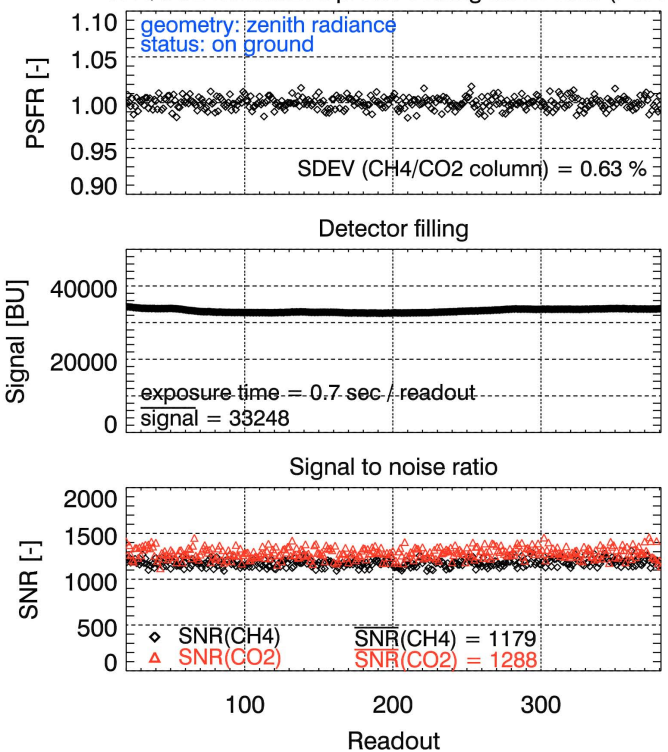

Fig. 8. Analysis of time series of MAMAP $\mathrm{CH}_{4}$ and $\mathrm{CO}_{2}$ measurements for slightly variable atmospheric conditions due to thin clouds for the 11 May 2006 stationary "on-ground" sun illuminated target (SIT) measurements. Left: top panel: normalized single readout $\mathrm{CH}_{4}$ (black) and $\mathrm{CO}_{2}$ (red) profile scaling factors (PSF). Second panel: normalized single readout $\mathrm{CH}_{4} / \mathrm{CO}_{2}$ profile scaling factor ratio (PSFR). Bottom panel: maximum radiance (detector filling) in binary units $[\mathrm{BU}]$ as measured with MAMAP and digitalized with $16 \mathrm{Bit}$ ADC. Right: as on left side but for 10 readouts co-added to one measurement.

MAMAP Caribbean Sea, 09-Nov-2008 (WHO)

$\mathrm{CH} 4 / \mathrm{CO} 2$ normalized profile scaling factor ratio (PSFR)
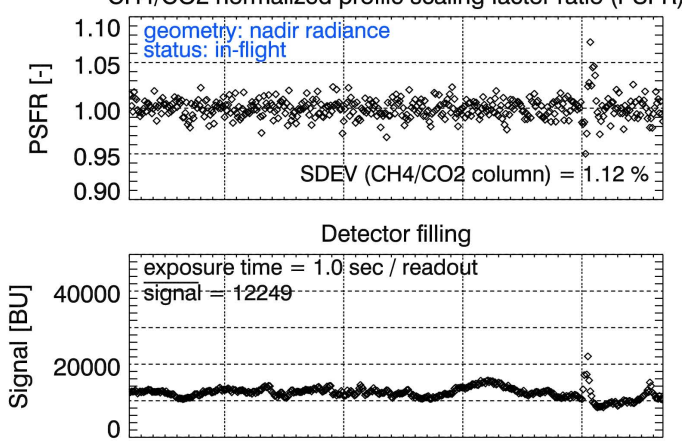

Signal to noise ratio

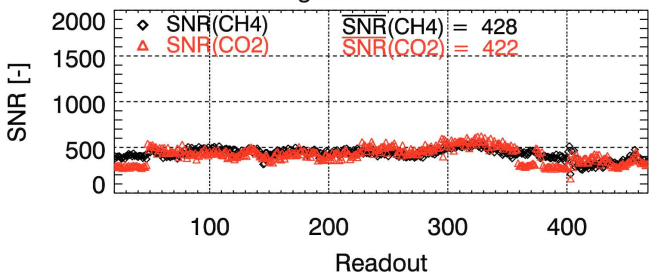

MAMAP Caribbean Sea, 09-Nov-2008 (WIH)

$\mathrm{CH} 4 / \mathrm{CO} 2$ normalized profile scaling factor ratio (PSFR)
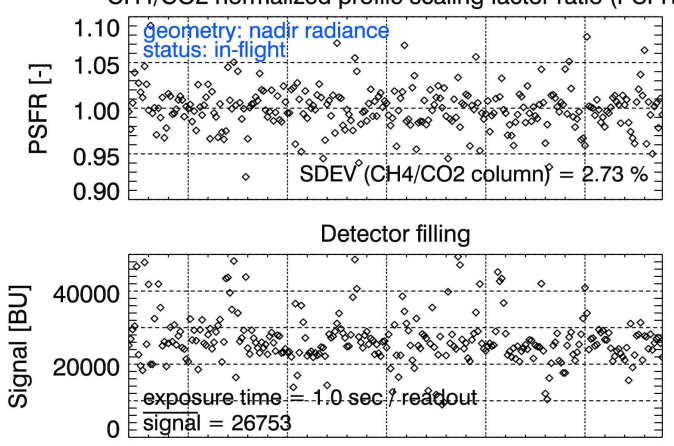

Signal to noise ratio

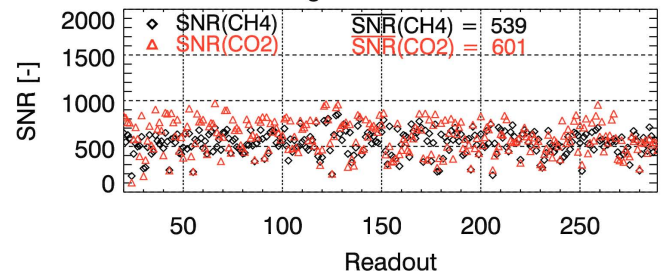

Fig. 9. As Fig. 8 but for in-flight nadir measurements over water; left: scene with homogeneous reflectance distribution (target WHO); right: scenes with inhomogeneous reflectance distribution (target WIH). 

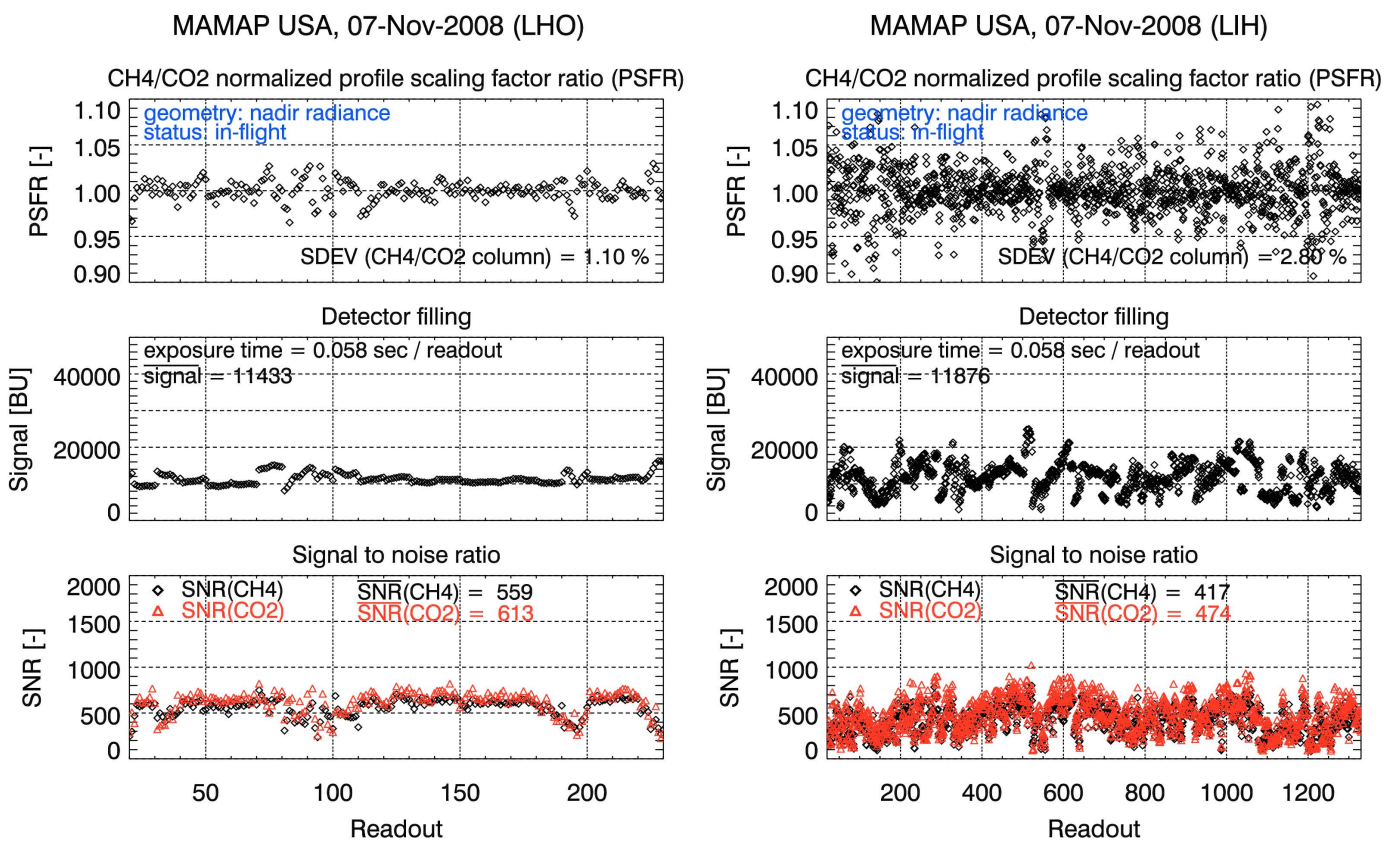

Fig. 10. As Fig. 8 but for in-flight nadir measurements over land; left: scene with homogeneous reflectance distribution (target LHO); right: scenes with inhomogeneous reflectance distribution (target LIH).

$\mathrm{CP} \%\left(\mathrm{CH}_{4}\right)$ - can be estimated from the PSFR precision and the conversion factor $c$ for $\mathrm{CH}_{4}$ (see Sect. 3) as:

$\mathrm{CP} \%\left(\mathrm{CH}_{4}\right) \approx \mathrm{PSFRP} \cdot c\left(\mathrm{CH}_{4}\right)$

For an aircraft altitude of $4500 \mathrm{~m}$, SZA of $40^{\circ}$ and an albedo/SSR of 0.01 the $\mathrm{CH}_{4}$ single readout column precision $\mathrm{CP} \%\left(\mathrm{CH}_{4}\right)$ for measurements over water with homogeneous radiance (WHO) can be estimated to $\sim 0.82 \%$ (for exposure time $=1 \mathrm{~s}$, albedo/SSR of 0.18 ). For the same plane altitude and SZA the single readout $\mathrm{CH}_{4}$ column precision over land surfaces with homogeneous radiance (LHO) can be estimated to $\sim 0.78 \%$ (for exposure time $=58 \mathrm{~ms}$ ). An according conversion factor can be applied in case of $\mathrm{CO}_{2}$.

\subsubsection{Airborne single readout measurements over inhomogeneous scenes}

To investigate effects of inhomogeneous illumination of the slit, airborne nadir measurement time series taken over water and land surfaces with inhomogeneous upwelling radiance were analyzed. The simulated and retrieved mean SNR values over water with inhomogeneous radiance deviate approximately by a factor of two $\left(\overline{\mathrm{SNR}}(\operatorname{sim})=1047\right.$ vs. $\overline{\mathrm{SNR}}(\mathrm{ret})=532$ for $\mathrm{CH}_{4}$ and $\overline{\mathrm{SNR}}(\operatorname{sim})=1063$ vs. $\overline{\mathrm{SNR}}($ ret $)=598$ for $\left.\mathrm{CO}_{2}\right)$. The according PSFR precisions were $0.42 \%$ (simulated) vs. $2.74 \%$ (retrieved) and deviate by a factor of $\sim 6.5$.

For land surfaces with inhomogeneous radiance similar results are obtained. The obtained simulated and retrieved mean SNR values were $\overline{\mathrm{SNR}}(\mathrm{sim})=628$ vs. $\overline{\mathrm{SNR}}($ ret $)=418$ for $\mathrm{CH}_{4}$ and $\overline{\mathrm{SNR}}(\mathrm{sim})=638$ vs. $\overline{\mathrm{SNR}}($ meas $)=475$ for $\mathrm{CO}_{2}$. The according PSFR precisions were $0.71 \%$ (simulated) vs. $2.8 \%$ (retrieved) and deviate by a factor $\sim 3.9$.

The degraded performance under inhomogeneous illumination conditions is attributed primarily to smile and keystone effects of the spectrometer system's optical bench, combined with an inhomogeneous illumination of the slit. This assumption is supported by ZEMAX ${ }^{\circledR}$ optical design program end to end simulations of the optical system of MAMAP, showing that inhomogeneous slit illumination leads to variations of the slit function shape and position. Such variations induce errors in the retrieval. Other factors like even-odd effects of the used linear InGaAs detector also caused by inhomogeneous illumination (i.e. even-odd effects due to tilted detector illumination) can be accounted for by the WFMD/M algorithm and are believed to play a minor role. Effects such as small spectral features of the earthshine spectral reflectance can also not be completely excluded as reason. All single readout time series results obtained for the different operation conditions are summarized in Table 3.

To minimize effects of inhomogeneous illumination of the slit, a modification of MAMAP's optical bench has been initiated. After this modification it is expected that the instrument will reach the same or similar performances as over surfaces with homogeneous radiance distribution.

Assuming concentration changes to only occur in the $\mathrm{CH}_{4}$ column below the aircraft and the $\mathrm{CO}_{2}$ column as constant, the $\mathrm{CH}_{4}$ single readout total column precision for a plane altitude of $4500 \mathrm{~m}$, SZA of $40^{\circ}$, albedo/SSR of 0.01 and exposure time of $1 \mathrm{~s}$ can be estimated to be $\sim 2.00 \%$ (see Table 2 
MAMAP Berlin, 02-Aug-2007 (ZIR)
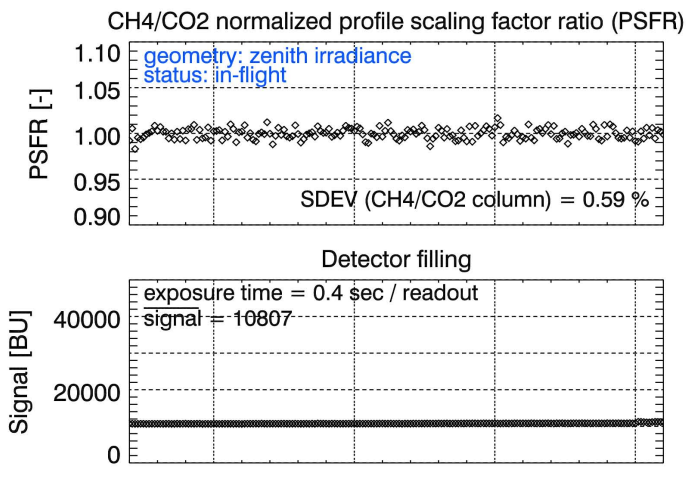

Signal to noise ratio

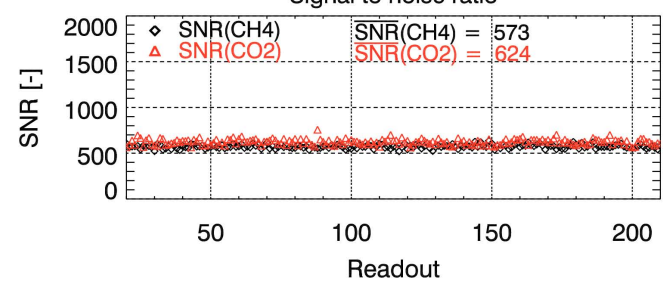

MAMAP USA, 07-Nov-2008 (LIH) (coadding $=10$ )

$\mathrm{CH} 4 / \mathrm{CO} 2$ normalized profile scaling factor ratio (PSFR)

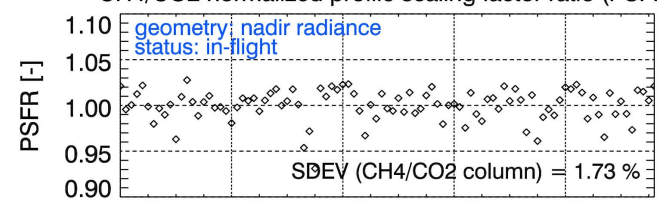

Detector filling

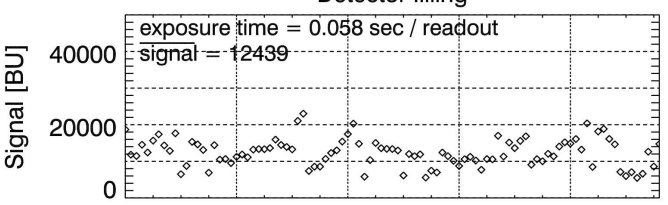

Signal to noise ratio

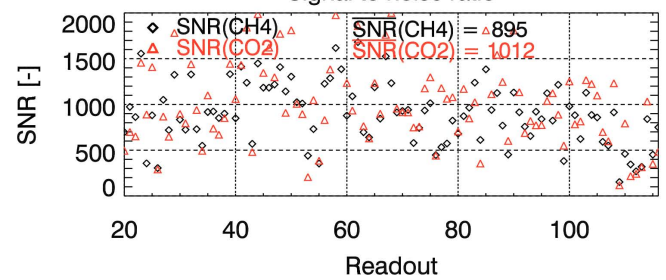

Fig. 11. As Fig. 8 but for in-flight measurements in zenith geometry and for nadir measurements over targets with inhomogeneous reflectance distribution; left: analysis of time series of single detector readout $\mathrm{MAMAP} \mathrm{CH}_{4}$ and $\mathrm{CO}_{2}$ dynamic "in-flight" zenith sky irradiance measurements (solar + hemispheric). Measurements performed over the MAMAP fiber optical inlet equipped with 4 transmissive Spectralon diffuser plates (target ZIR). Measurements conducted on 2 August 2007. Top panel: normalized $\mathrm{CO}_{2} / \mathrm{CH}_{4}$ profile scaling factor ratio (PSFR). Second panel: maximum irradiance (detector filling) in binary units [BU] as measured with MAMAP and digitalized with 16 Bit ADC. Bottom panel: estimated signal-to-noise ratios (SNR) of each measurements; right: as on left side but for co-added burst mode nadir measurements over land targets with inhomogeneous reflectance distribution (target LIH). Co-added measurements derived from measurements shown in Fig. 10 (right) but each burst of 10 measurements co-added and averaged (only measurements with $>3000$ [BU] are processed).

for conversion factors) for water with inhomogeneous radiance (WIH). For the same plane altitude and SZA the single readout $\mathrm{CH}_{4}$ column precision over land surfaces with inhomogeneous radiance ( $\mathrm{LIH}$ ) can be estimated to be $\sim 1.98 \%$ of the total column (for exposure time $=58 \mathrm{~ms}$ and albedo/SSR $\sim 0.18)$.

\subsubsection{MAMAP nominal co-added burst mode}

In this section, the MAMAP precision for the nominal burst mode of operation over land targets will be discussed. Over land targets typically bursts of 10 measurements were acquired and co-added to one measurement (see Sect. 2.1) to reach an appropriate $\mathrm{SNR}$ (i.e. $\mathrm{SNR} \approx 1000$ ). The retrieved burst mode SNR - SNR $\mathrm{BM}(\mathrm{ret})$ - and burst mode PSFR precision (PSFRP $\mathrm{BM}_{\mathrm{BM}}$ ) have been estimated in a similar way as for the single detector readouts (see Sects. 4.2 and 4.3), using the burst averaged residua and PSFR values, respectively.

The simulated and retrieved burst mode mean SNR values and PSFR precisions are summarized in Table 4. These were calculated for the same measurement series over land surfaces with inhomogeneous radiance (LIH) as described for single readouts in Sect. 4.3.3. In this section, only the worst case scenario (i.e. precision over surfaces with inhomogeneous radiance distribution) is investigated.
For integration times (=exposure time number of coadded spectra) of $\sim 580 \mathrm{~ms}$ the mean simulated vs. estimated $\overline{\mathrm{SNR}}_{\mathrm{BM}}$ values for measurements over surfaces with inhomogeneous radiance were $\overline{\operatorname{SNR}}_{\mathrm{BM}}(\operatorname{sim})=1986$ $\left(\mathrm{CH}_{4}\right)$ and $\overline{\mathrm{SNR}}_{\mathrm{BM}}(\mathrm{sim})=2017\left(\mathrm{CO}_{2}\right)$ vs. $\overline{\mathrm{SNR}}_{\mathrm{BM}}(\mathrm{ret})=827$ $\left(\mathrm{CH}_{4}\right)$ and $\overline{\mathrm{SNR}}_{\mathrm{BM}}(\mathrm{ret})=957\left(\mathrm{CO}_{2}\right)$. The respective simulated vs. retrieved burst mode PSFR precisions were $\operatorname{PSFRP}_{\mathrm{BM}}(\operatorname{sim})=0.225 \%$ vs. $\operatorname{PSFRP}_{\mathrm{BM}}($ ret $)=1.74 \%$. It is obvious that the retrieved burst mode precision is about a factor $\sim 7.7$ lower compared to the simulated values.

Assuming a Gaussian error distribution for the measurements, the burst mode PSFR precision and burst mode SNR can be derived for inhomogeneous targets (LIH) also in a indirect way. This was done by multiplication (i.e. for SNR calculation) or division (i.e. for precision calculation) of the retrieved single readout $\mathrm{SNR}\left(\overline{\mathrm{SNR}}_{\mathrm{SR}}(\mathrm{ret})\right)$ and single readout precision values $\left(\operatorname{PSFRP}_{\mathrm{SR}}(\mathrm{ret})\right)($ Sect. 4.3.3) with the square root of 10 (for $n=10$ measurements per burst).

The resulting indirectly derived mean burst mode SNR $\left(\overline{\mathrm{SNR}}_{\mathrm{BM}}(\mathrm{ret})^{\prime}\right)$ was $\overline{\mathrm{SNR}}_{\mathrm{BM}}(\mathrm{ret})^{\prime}=418 \cdot \sqrt{10}=1322$ for $\mathrm{CH}_{4}$ and $\overline{\mathrm{SNR}}_{\mathrm{BM}}($ ret $)=475 \cdot \sqrt{10}=1502$ for $\mathrm{CO}_{2}$. The according indirectly derived precision $\left(\operatorname{PSFRP}_{\mathrm{BM}}(\operatorname{sim})^{\prime}\right)$ was $\operatorname{PSFRP}_{\mathrm{BM}}(\operatorname{sim})^{\prime}=2.8 \% / \sqrt{10}=0.89 \%$. 
From the comparison of both directly derived and indirectly calculated SNR values and PSFR precisions $\left(\operatorname{SNR}_{\mathrm{BM}}(\mathrm{ret})\right.$ vs. $\overline{\mathrm{SNR}}_{\mathrm{BM}}(\mathrm{ret})^{\prime}$ and $\operatorname{PSFRP}_{\mathrm{BM}}(\mathrm{ret})$

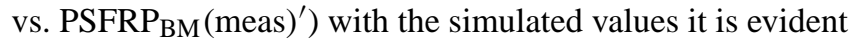
that random Gaussian error distribution can not be assumed for the single measured spectra.

This result supports the attribution of the random PSF errors observed with MAMAP to the inhomogeneous illumination of the spectrometer's slit and the variations in slit function position and shape, caused by keystone and smile effects. Ground structures like edges parallel to the flight direction can produce similar deviations in all 10 measurements of one burst. Therefore random Gaussian error distribution of the retrieved column errors can not be assumed. Spectral features in the earthshine spectral reflectance cannot be completely excluded either. In contrast, it is assumed that shot noise and noise of the readout electronics and the detector should produce random Gaussian error distributions like demonstrated for ground based measurements.

From these findings it can also be expected that the undergoing modification of the optical bench of the MAMAP instrument for reducing inhomogeneous slit illumination effects can lead to a significant improvement of the instrument's burst mode SNR and precision characteristics. Assuming that the instrument can then reach SNR and precision values similar to those achieved for single readouts over homogeneous land targets (LHO, Table 3), it can be estimated for burst mode, that SNR values in the order of $\overline{\mathrm{SNR}}_{\mathrm{BM}}(\text { meas })^{\prime}=538 \cdot \sqrt{10}=1713$ for $\mathrm{CH}_{4}$ and $\overline{\mathrm{SNR}}_{\mathrm{BM}}(\text { meas) })^{\prime}=588 \cdot \sqrt{10}=1859$ for $\mathrm{CO}_{2}$ remain feasible. The according feasible burst mode PSFR precision may reach a factor of $\sim 5$ better values than actually achieved (i.e. up to $\operatorname{PSFRP}_{\mathrm{BM}}(\mathrm{ret})^{\prime}=1.10 \% / \sqrt{10}=0.35 \%$ ).

Assuming again concentration changes to only occur in the $\mathrm{CH}_{4}$ column below the aircraft (and the $\mathrm{CO}_{2}$ column as constant), the actual MAMAP $\mathrm{CH}_{4}$ co-added burst mode total column precision $\left(\mathrm{CP}_{\mathrm{BM}, \%}\right)$ over inhomogeneous land surfaces $(\mathrm{LIH})$ can be estimated from the PSFR precision of $\sim 1.74 \%$ to be $\sim 1.23 \%(1 \sigma)$ for a plane altitude of $4500 \mathrm{~m}$, integration times of $580 \mathrm{~ms}$, SZA of $40^{\circ}$ and an albedo/SSR of 0.18 . For a background concentration of $1774 \mathrm{ppb}$ this corresponds to an enhancement of $21.8 \mathrm{ppb}$ of the total column.

By calculating the equivalent total column light path $L_{\mathrm{e}}$ through the atmosphere as $L_{\mathrm{e}}=g /(\rho g) \approx 8576 \mathrm{~m}$ (for $p=1013 \mathrm{hPa}, \rho=1.2041 \mathrm{~kg} \mathrm{~m}^{4}, g=9.81 \mathrm{~m} \mathrm{~s}^{-12}$ ) the total column precision of MAMAP is converted to ppm m for comparison with other instruments (SZA $40^{\circ}$, albedo/SSR 0.18):

$$
\mathrm{CP}\left(\mathrm{CH}_{4}\right)_{\mathrm{ppm} \mathrm{m}} \approx 21.8 \mathrm{ppb} \cdot 8576 \mathrm{~m}=187 \mathrm{ppm} \mathrm{m}
$$

For a typical SZA of $40^{\circ}$ the estimated column precision of $187 \mathrm{ppm} \mathrm{m}$ is inside the instrument threshold requirement, which is to measure the total column concentration in nadir with a precision of $1-2 \%$ with respect to the atmospheric background, corresponding to a precision of $\sim 150$ $300 \mathrm{ppm} \mathrm{m}$. For a lower plane altitude of $850 \mathrm{~m}$ the $1 \sigma$ precision becomes $142 \mathrm{ppm} \mathrm{m}$.

After the planned modification of the instruments optical bench to account for inhomogeneous slit illumination, a precision of the total column for a plane altitude of $850 \mathrm{~m}$ and integration time $t_{\text {int }}=600 \mathrm{~ms}$ of approximately

$$
\begin{aligned}
\mathrm{CP}\left(\mathrm{CH}_{4}\right)_{\mathrm{ppm} \mathrm{m}} & \approx 1774 \mathrm{ppb} \cdot 0.0035 \cdot c\left(\mathrm{CH}_{4}\right) \\
& =4.22 \mathrm{ppb}(\approx 33 \mathrm{ppm} \mathrm{m})
\end{aligned}
$$

is predicted.

In that case the MAMAP $\mathrm{CH}_{4}$ total column uncertainty variation will not be limited by the precision of the instrument. For a total column precision below $0.5 \%$, it can be expected, that the accuracy variation induced by atmospheric effects (i.e. light path differences for $\mathrm{CH}_{4}$ and $\mathrm{CO}_{2}$ caused by scattering and absorption of aerosols and clouds and variations of the albedo/SSR and refractive index of the atmosphere) will dominate the overall uncertainty variation.

\subsection{Spectral stability}

To investigate further the attribution of the degradation of the precision of MAMAP data products between inhomogeneous and homogeneous ground scenes to the inhomogeneous slit illumination and related model simulations, the short term spectral shifts in the observations over surfaces having respectively homogeneous and inhomogeneous radiance were analysed. It is assumed that any impact of the aircraft vibration for the different measurement series are similar. A comparison of short term spectral shifts derived by non-linear least squares fitting for inhomogeneous and homogeneous water surfaces shows a change of up to a factor of two: spectral shifts being $0.0049 \mathrm{~nm}$ for homogeneous scenes as compared to $0.0101 \mathrm{~nm}$ for inhomogeneous scenes above water. For land surfaces a similar deviation was observed: the spectral shift being $0.0180 \mathrm{~nm}$ for homogeneous compared to $0.0364 \mathrm{~nm}$ for inhomogeneous land surfaces. The different exposure times of $1 \mathrm{~s}$ over water and $58 \mathrm{~ms}$ over land and the difference in inhomogeneity distribution between land and water surfaces are attributed to the differences in the observed shifts. Thus the factor of two decrease in spectral stability in both cases (for land and for water) is consistent with a degraded performance of MAMAP being explained by inhomogeneous illumination effects of the spectrometers slit. For comparison, additionally to the airborne nadir measurements spectral shift results from ground based radiance and airborne zenith sky irradiance measurements are summarized in Table 6. MAMAP achieves for the fastest exposure times over homogeneous land targets (LHO), where the spectral shifts are expected to be dominated primarily by vibrations, a spectral stability of $\sim 1 / 46$ of the FWHM of $0.82 \mathrm{~nm}$ (i.e. close to the required value of $1 / 60$ of the FWHM). 


\section{MAMAP targets}

Achieving 1-2\% total column precision (and relative accuracy) for the data products $\mathrm{XCH}_{4}$ and $\mathrm{XCO}_{2}$ from a single ground scene measurement (corresponding to 150 $300 \mathrm{ppm} m-1 \sigma-$ column change for $\mathrm{CH}_{4}$ and $33000-$ $66000 \mathrm{ppmm}$ for $\mathrm{CO}_{2}$ below the aircraft; see Sect. 4), is challenging for an airborne passive SWIR remote sensing instrument. Nevertheless, such a performance puts limitations on the target emissions which are suitable to be detected. In the following we will make an estimate based on the actually achieved MAMAP total column precision of $\approx 1 \%$. Thereby it will be assumed, that a total column relative accuracy (neglecting a constant bias) of $<\approx 1 \%$ can be achieved on small scales (i.e. several kilometers) for clear sky atmospheric conditions when no aerosols are produced by the source itself. The assumption is justified by the theoretical error analysis performed on $\mathrm{XCH}_{4}$ SCIAMACHY data (see for WFM-DOAS $\mathrm{XCH}_{4}$ from SCIAMACHY also Schneising et al., 2008, 2009; Schneising, 2009). A detailed relative accuracy analysis including also aerosols produced by the source itself will be presented in a separate publication (Krings et al., 2011).

Because of the large background concentrations of $\mathrm{CH}_{4}$ and $\mathrm{CO}_{2}$, an emission source must have an appropriate emission strength and horizontal extent in order to build up a column enhancement which can be detected.

In the following we discuss the conditions under which MAMAP can obtain information about supposed target emissions. For this purpose we use a simple model to relate the surface flux $F$ of a given gas to the relative change of its vertical column $\Delta V / V$ over a distance $l$ along the main wind direction. In this section two cases are considered: (i) a range of targets from a well isolated source region of the size of a MAMAP footprint up to an area observed by MAMAP in several minutes, i.e. $\sim 25 \mathrm{~m}$ up to a few $10 \mathrm{~km}$. Possible targets are landfills, seeps, fugitive emissions of gas/oil industry, power plants, steelworks, coal mines and (mud) volcanoes, (ii) an effectively homogeneous source region with an extension larger than $\sim 50 \mathrm{~km}$ such as extended wetlands.

For an isolated source region, time independent (static) meteorological conditions can be assumed as a first approximation for short periods of time where measurements are taken over and near the source. These conditions are characterized by clear sky over the measurement area, small atmospheric variations of the cloud and aerosol optical thickness, small solar zenith angle variations and nearly constant wind speeds. For such conditions, systematic accuracy variations in the $\mathrm{CH}_{4} / \mathrm{CO}_{2}$ column caused by light path differences induced primarily by an inadequate modelling of the scattering of electromagnetic radiation by aerosols and optically thin cirrus clouds (Schneising et al., 2009; Schneising, 2009) is assumed to be small and was hence neglected in a first approximation (Krings et al., 2011).
Table 6. MAMAP SWIR relative single readout detector spectral stability (readout to readout) as retrieved by best estimate of the WFMD/M algorithm for different reference targets for a slit function FWHM of $0.82 \mathrm{~nm}$ for different dynamic in flight and static on ground measurements. The different stability values are not directly comparable because of different exposure times during the measurements. Comparison of the shift values for different conditions give only a raw estimate for short time spectral shifts caused by vibrations and short time spectral shifts caused by inhomogeneous illumination of the slit induced by keystone and smile effects of the spectrometer.

\begin{tabular}{lcccl}
\hline Target & $t_{\text {exp }}$ & $\begin{array}{c}\text { SDEV } \\
\text { spectral shift } \\
{[\mathrm{nm}]}\end{array}$ & $\begin{array}{c}\text { SDEV } \\
\text { spectral shift } \\
{[\%]}\end{array}$ & $\begin{array}{l}\text { Observation } \\
\text { conditions }\end{array}$ \\
\hline WHO & 1.000 & 0.0049 & 0.60 & in flight \\
WIH & 1.000 & 0.0101 & 1.23 & in flight \\
LHO & 0.058 & 0.0180 & 2.20 & in flight \\
LIH & 0.058 & 0.0364 & 4.45 & in flight \\
ZIR & 0.400 & 0.0041 & 0.50 & in flight \\
ZRG & 0.700 & 0.0017 & 0.21 & on ground \\
SIT & 0.148 & 0.0009 & 0.11 & on ground \\
\hline
\end{tabular}

Depending on source size and the assumption that background aerosol and cirrus clouds are smoothly varying, the impact of slow systematic changes in the accuracy of the measured $\mathrm{CH}_{4} / \mathrm{CO}_{2}$ column mixing ratio can optionally be further minimised by high-pass filtering the data. Strong local sources produce short term or small scale concentration changes for the flight path compared to changes produced by variations in background aerosols and (thin) cirrus clouds. For such conditions it can be assumed that the detection limit of MAMAP is primarily dominated by the instrument precision rather than by variation of the accuracy when no aerosol is produced by the source itself.

Assuming a constant wind speed $u$ in the horizontal $+x$ direction in the layer of interest and a mean flux $F$ as first approximation, the resulting enhancement $\Delta V$ of the vertical column $V$ can be estimated as follows: $\Delta V=F \cdot t$, where $t$ is the accumulation time, which characterizes the time available for an air column to accumulate $\mathrm{CH}_{4}$ when it moves over the target. For a target with extension $l$ it follows $t=l / u$. The relative increase of the vertical column over the target is given by $\Delta V / V=F / V \cdot l / u$. The smallest detectable flux $F_{\text {min }}$ for a given situation is then given by:

$F_{\min }=\Delta V / V \cdot V \cdot u / l$.

For the estimation we assume a constant wind speed of $u=2 \mathrm{~m} \mathrm{~s}^{-1}$ and all concentration changes to occur below the aircraft, a horizontal extent of the emission source of $l \approx 400 \mathrm{~m}$ (e.g. a landfill) and the required total column enhancement $\Delta V / V$ equal to $\sim 1 \%$ total column precision $\left(\sim 150 \mathrm{ppm} \mathrm{m}\right.$ for $\mathrm{CH}_{4}$ and $32600 \mathrm{ppm} \mathrm{m}$ for $\left.\mathrm{CO}_{2}\right)$ 
of MAMAP for inhomogeneous scenes. With a typical value for the $\mathrm{CH}_{4}$ background column of $V=10 \mathrm{~g} \mathrm{CH}_{4} \mathrm{~m}^{-2}$ $\left(3.6 \times 10^{19}\right.$ molecules $\left.\mathrm{cm}^{-2}\right)$ the smallest detectable flux $F_{\min }$ can then be calculated to be $1.8 \mathrm{~g} \mathrm{CH}_{4} \mathrm{~m}^{-2} \mathrm{~h}^{-1}$. At a constant wind speed of $2 \mathrm{~m} \mathrm{~s}^{-1}$ the product of flux $F$ and source extension $l$ is the main parameter which can be calculated for $1 \% \mathrm{CH}_{4}$ enhancement to be $F_{\min } \cdot l=0.01 \cdot 10 \mathrm{~g} \mathrm{CH}_{4} \mathrm{~m}^{-2} \cdot 2 \mathrm{~m} \mathrm{~s}^{-1}=0.2 \mathrm{~g} \mathrm{CH}_{4} \mathrm{~m}^{-1} \mathrm{~s}^{-1}$. Equivalent calculations can also be performed for $\mathrm{CO}_{2}$.

Over the globe, many different sources exist with fluxes exceeding the above calculated detection limits. For instance $\mathrm{CH}_{4}$ emissions of landfills with organic waste and temporal coverage, equipped with gas recovery can reach mean $\mathrm{CH}_{4}$ fluxes in the order of $2-4 \mathrm{~g} \mathrm{CH}_{4} \mathrm{~m}^{-2} \mathrm{~h}^{-1}$ (Fellner et al., 2003; Börjesson et al., 2000), i.e., larger than the actual detection limit of MAMAP. Furthermore Judd (2004) report $\mathrm{CH}_{4}$ fluxes between 148 and $445 \mathrm{~g} \mathrm{CH}_{4} \mathrm{~m}^{-2} \mathrm{~h}^{-1}$ for the Coal Oil Point (COP) seep measured with tents for an area of $1800 \mathrm{~m}^{2}$ near Santa Barbara, California. Miscellaneous strong dry seeps and mud volcanoes exist also in other parts of the world for instance at the Black Sea shelve offshore Georgia (Judd, 2004), in eastern Azerbaijan (Etiope et al., 2004) and Indonesia (Chakraborty and Anggraini, 2009). Strong seepage can also occur over shallow or submerged gas hydrates in arctic regions (Shakhova et al., 2010; Bowen et al., 2008). Other localized sources like fugitive emissions as the result of oil and gas well exploration and utilization by oil and gas industry can produce atmospheric fluxes strong enough to be detected with MAMAP as well. Jagovkina et al. (2000, and references therein) estimated for an area of $\sim 1.8 \cdot 10^{10} \mathrm{~m}^{2}$ near Yamal in Russia a mean flux of $1-2 \mathrm{~g} \mathrm{CH}_{4} \mathrm{~m}^{-22} \mathrm{~d}^{-1}$. The corresponding detection limit of MAMAP for such an area (e.g. extend of $l \approx 50 \mathrm{~km}$ ) can be calculated to be in the range of $F_{\min } \approx 0.35 \mathrm{~g} \mathrm{CH}_{4} \mathrm{~m}^{-2} \mathrm{~d}^{-1}$ which is well below the reported values. Similar estimates can be performed for refineries and gas processing plants with fugitive emissions in the range of $\sim 140-300 \mathrm{~kg} \mathrm{CH}_{4} \mathrm{~h}^{-1}$ (Chambers and Strosher, 2006a,b). Emissions from oilsands tailings settling basins with flux estimates between $0.1-4.8 \mathrm{~g} \mathrm{CH}_{4} \mathrm{~m}^{-2} \mathrm{~h}^{-1}$ (Siddique et al., 2008) also outrun the smallest detectable fluxes. Beside $\mathrm{CH}_{4}$ also anthropogenic and geologic $\mathrm{CO}_{2}$ emission from volcanoes (Mörner and Etiope, 2002), coal fired power plants, steelworks, cement production etc. (EPER, 2004) clearly exceed the detection limit of MAMAP.

These estimates show that MAMAP has the potential to detect strong local $\mathrm{CH}_{4}$ and $\mathrm{CO}_{2}$ emissions and corresponding gradients as shown in the next section. Under certain circumstances (i.e. knowledge of wind) also corresponding fluxes can be more accurately estimated or constrained when appropriate patterns are flown (Krings et al., 2011) as current flux uncertainties for several anthropogenic and geologic sources can reach values of up to $50-100 \%$ (NRC, 2010). After finalizing the modification of the optical system of MAMAP, it can be expected that the smallest detectable flux limit $F_{\min }$ can be improved significantly. In addition appropriate flight strategies allowing further averaging of the observations can also improve the precision. Thus detection of weaker localized sources can be expected in the future.

Many important $\mathrm{CH}_{4}$ sources emit significantly smaller fluxes of $\mathrm{CH}_{4}$ compared to the values reported above (for localized sources). Siberian wetlands emit typically in the order of $\sim 20 \mathrm{mg} \mathrm{CH}_{4} \mathrm{~m}^{-2} \mathrm{~d}^{-1}$ on average (Sachs et al., 2008) up to $\sim 200 \mathrm{mg} \mathrm{CH}_{4} \mathrm{~m}^{-2} \mathrm{~d}^{-1}$ for summer seasons (Bohn et al., 2007). The approach used above can also be applied to estimate the detection limits required for extended regions of less intense source emissions assuming that the region is sufficiently homogeneous. For a strong summer $\mathrm{CH}_{4}$ flux of $F=200 \mathrm{mg} \mathrm{CH}_{4} \mathrm{~m}^{-2} \mathrm{~d}^{-1}$ for Western Siberian wetlands, a constant wind speed of $u=2 \mathrm{~m} \mathrm{~s}^{-1}$, and a minimum detectable column enhancement of $\Delta V / V=1 \%$ (corresponding to $150 \mathrm{ppm} \mathrm{m}$ below the aircraft), a required accumulation distance of $l \approx 86 \mathrm{~km}$ can be calculated. In order to estimate gradients typically a larger distance is required (i.e. min. 3 times of the accumulation distance, $\sim 250 \mathrm{~km}$ ). This simple method to estimate the range of expected $\mathrm{CH}_{4}$ total column changes emanating from these type of sources requires sufficiently stable conditions during the period of the aircraft measurement. When this requirement is not fulfilled, more complex regional chemical transport modelling (Jagovkina et al., 2000, 2001) is needed. It has to be noted that for extended sources the smallest detectable flux $F_{\min }$ is restricted primarily by accuracy variations (i.e. the relative accuracy) and not by the precision of the instrument. A detailed discussion on the impact of aerosols, albedo, thin clouds and other effect on the accuracy/relative accuracy of MAMAP data products will be given in Krings et al. (2011).

\section{First results from measurements over localized emissions sources}

In order to test the MAMAP sensitivity to score emissions and to compare with results obtained in Sects. 4.3.1 and 5 flights over localized targets have been performed in summer 2007. In the following, results from flights over a target with poorly known $\mathrm{CH}_{4}$ emission rate (i.e. a landfill) and targets with well characterized $\mathrm{CO}_{2}$ emission rates (i.e. two power plants) are presented.

The flights were performed with a Cessna 207 aircraft, operated by the Free University of Berlin. The flights over the well characterized $\mathrm{CO}_{2}$ targets focused on the coal fired power plants Jänschwalde and Schwarze Pumpe (located near Berlin, Germany). In the following we present results obtained with the SWIR channel for nadir observations only. Zenith observations are to be included in the retrieval algorithm in a subsequent studies.

The measurements were analyzed with the WFMD/M retrieval algorithm (see Sect. 3) using radiative transfer 
simulations performed with the SCIATRAN radiative transfer model (Rozanov et al., 2005).

The conditions of flight were such that the aircraft flew at $850 \mathrm{~m}$ altitude performing direct nadir observations. By computing the $\mathrm{CO}_{2} / \mathrm{CH}_{4}$ ratio of the measured and retrieved profile scaling factors for the $\mathrm{CO}_{2}$ sources (assuming that $\mathrm{CH}_{4}$ is constant) and vice versa $\left(\mathrm{CH}_{4} / \mathrm{CO}_{2}\right)$ for the $\mathrm{CH}_{4}$ source (assuming that $\mathrm{CO}_{2}$ is constant), any line-of-sight errors, induced by rolling of the aircraft and lack of knowledge of altitude/ground distance were neglected (see Sect. 3). Each flight of each day was processed for one fixed altitude and one fixed solar zenith angle. Systematic effects in the measured columns caused by solar zenith angle changes, changes in altitude and low frequency cirrus cloud variations are minimised by applying an 80 point high-pass filter to the co-added burst mode data (see previous section). Compared to the extend of the investigated sources this filter removes primarily low frequency variations not caused by the emissions of the source.

For the RTM simulation, temperature, pressure, and water vapour vertical profiles corresponding to the US Standard Atmosphere, a constant albedo/SSR of 0.18 and a solar zenith angle of $40^{\circ}$ (as calculated for the time of the overfligts) have been used. Clear sky (cloud free) conditions have been assumed although some partial cirrus covers have been reported during the flights.

Figures 12 and 13 show retrieved and normalized $\mathrm{CO}_{2} / \mathrm{CH}_{4}$ PSF ratios of MAMAP measurements of the power plant overflights near Berlin performed on 26 July 2007.

The target shown in Fig. 12 was the power plant Jänschwalde, operated by Vattenfall. This coal-fired power plant emits approximately $24.9 \mathrm{MtCO}_{2} \mathrm{yr}^{-1}$ (EPER, 2004). On 26 July 2007 the plant emitted $56.6 \mathrm{tCO}_{2} \mathrm{~min}^{-1}$ (Dietmar Heinze, Vattenfall Europe Generation AG \& Co. KG, Cottbus, Germany, personal communication, 2008). We estimated (depending on wind speed) that this emission roughly corresponds to a $\mathrm{CO}_{2}$ total column increase (which is about $8 \times 10^{21}$ molecules $\mathrm{cm}^{-2}$ for a surface pressure of about $1000 \mathrm{hPa}$ and a $\mathrm{CO}_{2}$ mixing ratio of $\left.380 \mathrm{ppm}\right)$ of few percent over and near the power plant (see Bovensmann et al., 2010).

The flight pattern has been chosen such that the aircraft was crossing several times the plume. The wind direction, which was almost perpendicular to the flight track, was clearly visible by the small steam clouds over the cooling towers (see photo Fig. 12). As can be seen in Fig. 12, elevated atmospheric $\mathrm{CO}_{2}$ originating from the power plant and transported in wind direction, can clearly be detected with MAMAP. The elevated $\mathrm{CO}_{2}$ is readily observed in the small map (on the right) showing the $\mathrm{CO}_{2}$ PSF retrieved by the WFMD/M algorithm. The $\mathrm{CH}_{4}$ PSF (the small map below) does not show such a clear pattern. This is as expected as there are no known local strong sources of $\mathrm{CH}_{4}$ near the power plant. Also as expected, the ratio of the $\mathrm{CO}_{2}$ to $\mathrm{CH}_{4}$
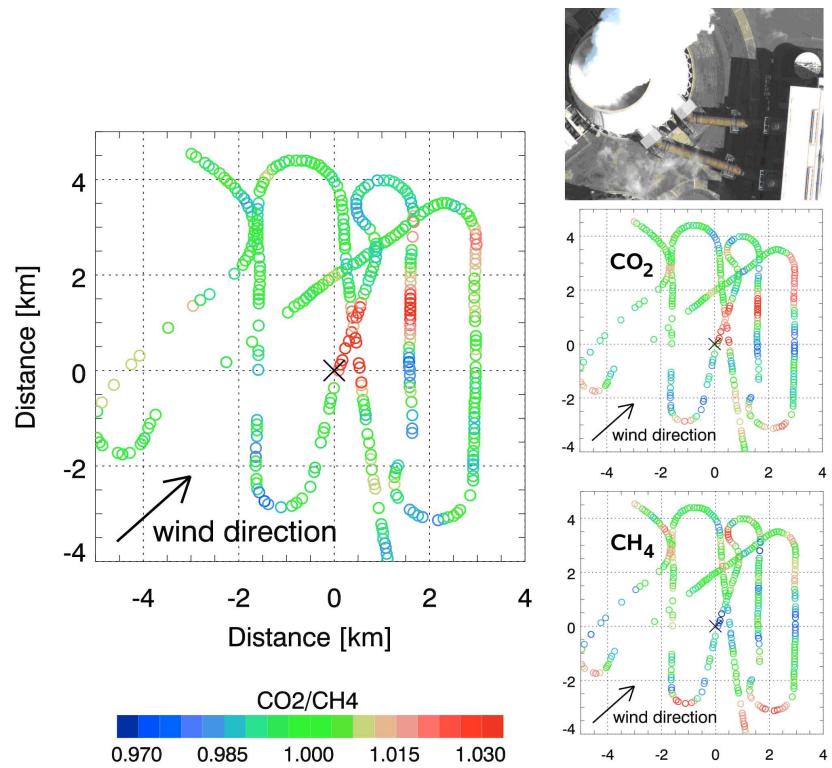

Fig. 12. Left: normalized MAMAP $\mathrm{CO}_{2} / \mathrm{CH}_{4}$ profile scaling factor ratio $\left(\mathrm{PSFR}_{\mathrm{BM}}\right)$ retrieved from measurements acquired on 26 July 2007 over the power plant Jänschwalde (black cross) located north of Cottbus (south-east of Berlin) in Eastern Germany, right: photo automatically taken during the flight over the power plant (top), dimensionless $\mathrm{CO}_{2}$ profile scaling factors (middle), and dimensionless $\mathrm{CH}_{4}$ profile scaling factors (bottom). All values shown in a given map as part of the flight have been scaled with a constant factor such that the scaled values of the whole flight are close to unity (green). The data have been smoothed using a seven point moving average and high-pass filtered with a 80 point high-pass filter. Gaps are due to the quality filtering (shown are only measurements where the spectral signal was larger than 3000 counts after dark signal correction and the root-mean-square (RMS) of the fit residuum, i.e. the relative difference between measurement and model after the fit, is better than $1 \%$ ). The $\mathrm{CO}_{2}$ output of the power plant during the overflight was $56.6 \mathrm{t} \mathrm{min}^{-1}$ (Dietmar Heinze, Vattenfall Europe Generation AG \& Co. KG, Cottbus, Germany, personal communication, 2008).

profile scaling factors produce a smoother pattern, as light path errors due to, e.g., not yet considered changes of the aircraft rolling and distance to ground, cancel to a large extent when the $\mathrm{CO}_{2} / \mathrm{CH}_{4} \mathrm{PSF}$ ratio is computed. The approximately $3 \%$ enhancement in the $\mathrm{CO}_{2} / \mathrm{CH}_{4} \mathrm{PSF}$ ratio over the power plant shown in Fig. 12 is attributed to elevated $\mathrm{CO}_{2}$. Assuming the changes of $\mathrm{CH}_{4}$ as small and $\mathrm{CO}_{2}$ variations to occur only below the aircraft the total column increase $\Delta C_{\mathrm{TC}}$ of $\mathrm{CO}_{2}$ is estimated from the $3 \%$ enhancement of the PSF ratio by:

$\Delta C_{\mathrm{TC}}\left(\mathrm{CO}_{2}\right) \approx 380 \mathrm{ppm} \cdot 0.03 \cdot c\left(\mathrm{CO}_{2}\right)=4.86 \mathrm{ppm}$

which is in agreement with values obtained by Gaussian plume model simulations (Krings et al., 2011; Bovensmann et al., 2010). These results show that MAMAP reaches the initial sensitivity requirements very well. For more details on 

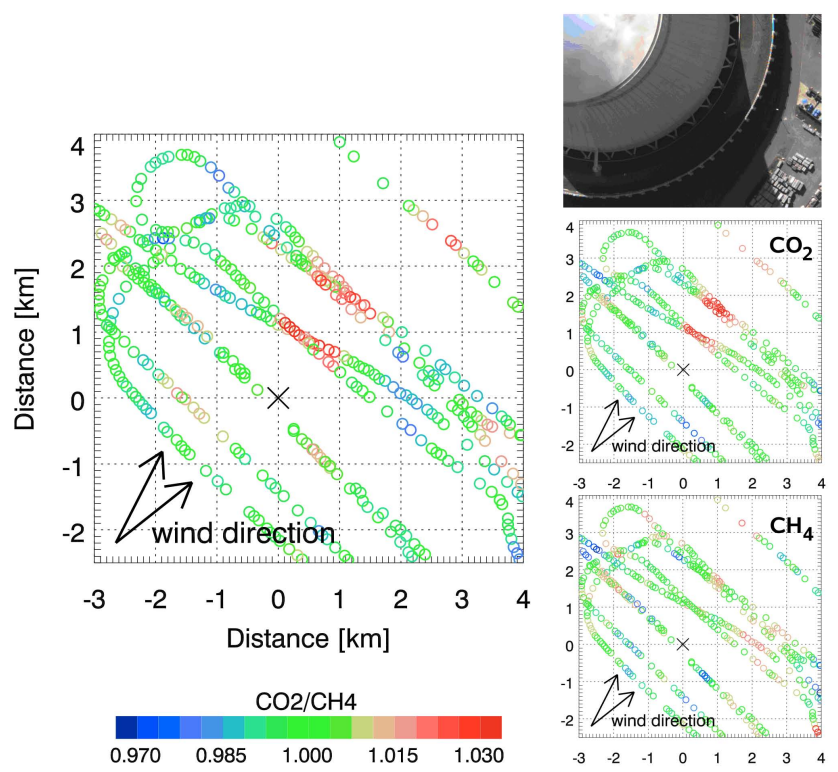

Fig. 13. As Fig. 12 but for the power plant Schwarze Pumpe located near the power plant Jänschwalde. The $\mathrm{CO}_{2}$ output of the power plant was $26 \mathrm{t} \mathrm{min}^{-1}$ during the overflights (Vattenfall Europe Generation AG \& Co. KG, Cottbus, Germany, personal communication, 2008).

power plant emission measurement with MAMAP and associated inversion of fluxes see also Krings et al. (2011).

Figure 13 shows similar results as Fig. 12 but for overflights at the power plant Schwarze Pumpe, which has an output of approximately $10.9 \mathrm{MtCO}_{2} \mathrm{yr}^{-1}$ (EPER, 2004). On the 26 July 2007 Schwarze Pumpe had an output of $26 \mathrm{tCO}_{2} \mathrm{~min}^{-1}$ as reported by Vattenfall. The wind speed during both overflights was in the range of $\sim 2.5-5.0 \mathrm{~m} \mathrm{~s}^{-1}$. The figure shows that enhanced $\mathrm{CO}_{2}$ values can clearly be observed downwind of the source with MAMAP.

Figure 14 shows an overflight transect measured over the landfill Vorketzin on 26 July 2007. During the transect wind speed was measured nearby the landfill. The mean wind speed was estimated to be in the order of $3 \mathrm{~m} \mathrm{~s}^{-1}$ from south, south-south-west direction. The path length of the accumulation of the air-mass over the landfill body is estimated to about $\sim 450 \mathrm{~m}$.

The anomaly in the retrieved normalized $\mathrm{CH}_{4} / \mathrm{CO}_{2} \mathrm{PSF}$ ratio during the transect was in the range of $+1-2 \%$ (Fig. 14). With a SZA of $\sim 40^{\circ}$ and an aircraft altitude of $\sim 850 \mathrm{~m}$ and the assumption that the observed anomaly (of $2 \%$ ) is mainly due to the increase of the $\mathrm{CH}_{4}$ concentration below the aircraft, the corresponding enhancement in total column (for albedo/SSR of $\sim 0.18$ ) can be estimated to:

$$
\begin{aligned}
\Delta T_{\mathrm{CT}, \%}\left(\mathrm{CH}_{4}\right) & \approx 0.02 \cdot c\left(\mathrm{CH}_{4}\right) \\
= & 0.0107 \approx 1.11 \% \text { total column increase }
\end{aligned}
$$

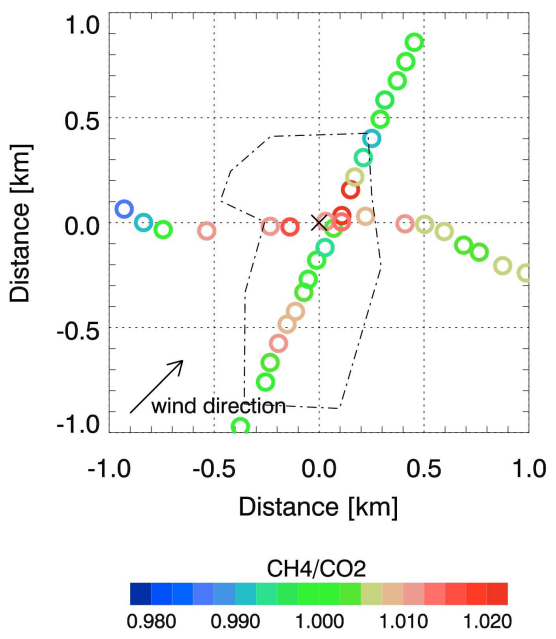

Fig. 14. Normalized $\mathrm{CH}_{4} / \mathrm{CO}_{2}$ profile scaling factor ratio $\left(\mathrm{PSFR}_{\mathrm{BM}}\right)$ showing anomaly in the upper part of the landfill Vorketzin located near Berlin in Eastern Germany. Data acquired with MAMAP on 26 July 2007. The data have been smoothed using a three point moving average. Gaps are due to the quality filtering: shown are only measurements where the spectral signal was larger than $3000[\mathrm{BU}]$ after dark signal correction and the rootmean-square (RMS) of the fit residuum (relative difference between measurement and model after the fit) is better than $1 \%$. The dashed line shows the landfill body. To remove low frequency variations data were filtered with a 80 point high-pass filter.

Assuming movement of the air-mass with constant speed $\left(3 \mathrm{~m} \mathrm{~s}^{-1}\right)$ over the landfill body and that the adjacent wet-lands produce much less $\mathrm{CH}_{4}$ (typically $<60 \mathrm{mg} \mathrm{CH}_{4} \mathrm{~m}^{-2} \mathrm{~d}^{-1}$ ) than the landfill body itself, the $\mathrm{CH}_{4}$ total column increase of $\sim 0.56-1.11 \%$ (after $450 \mathrm{~m}$ ) leads to a rough estimate of the mean emission rate for the upper central landfill area within $\sim 1.24-2.48 \mathrm{~g} \mathrm{CH}_{4} \mathrm{~m}^{-2} \mathrm{~h}^{-1}$ or larger. For similar types of landfills (with organic waste, equipped with temporal covers and gas recovery systems) mean flux rates to the atmosphere in the order of $2-4 \mathrm{~g} \mathrm{CH}_{4} \mathrm{~m}^{-2} \mathrm{~h}^{-1}$ are reported (Fellner et al., 2003; Börjesson et al., 2000) as discussed in the previous section.

To verify the $\mathrm{CH}_{4} / \mathrm{CO}_{2}$ proxy approach for estimating landfill emissions and exclude any impact from landfill $\mathrm{CO}_{2}$ emissions on the retrieved $\mathrm{XCH}_{4}$ total column increase it was assumed that the estimated $\mathrm{CH}_{4}$ fluxes of $\sim 1.24-2.48 \mathrm{~g} \mathrm{CH}_{4} \mathrm{~m}^{-2} \mathrm{~h}^{-1}$ were induced only by $25 \%$ of the total landfill $\mathrm{CH}_{4}$ production. Thus the fraction of $3.72-7.14 \mathrm{~g} \mathrm{CH}_{4} \mathrm{~m}^{-2} \mathrm{~h}^{-1}$ was oxidized and emitted as $\mathrm{CO}_{2}$ corresponding to a $\mathrm{CO}_{2}$ flux to the atmosphere of $10.21-20.42 \mathrm{~g} \mathrm{CO}_{2} \mathrm{~m}^{-2} \mathrm{~h}^{-1}$. With a wind speed of $3 \mathrm{~m} / \mathrm{s}$ and a $\mathrm{CO}_{2}$ atmospheric background concentration of $8.192 \times 10^{21}$ molecules $\mathrm{cm}^{-2}$ it can be estimated, that the resulting $\mathrm{CO}_{2}$ total column increase will be $<0.01 \%$ after $450 \mathrm{~m}$ and therefore could be neglected in the calculation. 
To also exclude albedo/SSR dependent offsets as origin of the $\mathrm{CH}_{4}$ column increase, an empirical assessment of the data from the whole flight has been performed. From the assessment a linear equation

$$
\Delta \operatorname{PSFR}\left(\mathrm{CH}_{4} / \mathrm{CO}_{2}\right)=\Delta R \cdot(-0.38) \times 10^{-4}
$$

was derived by linear regression as first approximation of the dependency between the retrieved difference ( $\triangle \mathrm{PSFR}\left(\mathrm{CH}_{4} / \mathrm{CO}_{2}\right)$ ) of the normalized $\mathrm{CH}_{4} / \mathrm{CO}_{2} \mathrm{PSF}$ ratio, and the variation of the upwelling radiance $\Delta R$ in binary units (BU). The correlation coefficent of the linear fit to the measured data $(\approx 0.2)$ was not very high but gives a first guess for the signal (and also for the albedo/SSR) dependency of the retrieved $\mathrm{CH}_{4} / \mathrm{CO}_{2}$ PSFR also including other signal dependent effects like nonlieratity of the detector.

The difference in the measured upwelling radiance during the landfill transect was in the order of $\Delta R \approx 2000-6000 \mathrm{BU}$ (centre - side variations during the transect). Assuming that the observed radiances $R$ (and corresponding detector fillings) are proportional to variations of the albedo/SSR, the resulting absolute value of the albedo/SSR dependent offset of the normalized $\mathrm{CH}_{4} / \mathrm{CO}_{2}$ PSF ratio for the landfill transect can be estimated to be: $\triangle \operatorname{PSFR}\left(\mathrm{CH}_{4} / \mathrm{CO}_{2}\right) \approx 0.076-$ $0.228 \%$. The albedo/SSR dependent total column variation $\left(\triangle \mathrm{AC}_{\mathrm{TC}, \%}\right)$ is then calculated to

$$
\begin{aligned}
\Delta \mathrm{AC}_{\mathrm{TC}, \%}\left(\mathrm{CH}_{4}\right) & =\Delta \operatorname{PSFR}\left(\mathrm{CH}_{4} / \mathrm{CO}_{2}\right) \cdot c\left(\mathrm{CH}_{4}\right) \\
& \approx 0.041-0.122 \%
\end{aligned}
$$

offset of the total column. Thus the albedo/SSR dependent variation in the retrieved $\mathrm{CH}_{4}$ total column is smaller than the retrieved total column increase of $\sim 0.56-1.11 \% \mathrm{CH}_{4}$ during the transect.

\section{Summary}

The Methane Airborne MAPper (MAMAP) is a new type of passive airborne remote sensing instrument, which measures the back scattered electromagnetic radiation in the spectral regions of the $\mathrm{CH}_{4}, \mathrm{CO}_{2}$ and $\mathrm{O}_{2}$ atmospheric absorptions. On inversion using differential optical absorption spectroscopy (DOAS), the reflected (and scattered) solar radiation in the NIR and SWIR spectral range yield the column and dry column amounts of $\mathrm{CH}_{4}$ and $\mathrm{CO}_{2}$ and the ratio of $\mathrm{CH}_{4}$ to $\mathrm{CO}_{2}$. The instrument has been designed for flexible operation on board of several airborne platforms (e.g., Cessna 207, Cessna Caravan and AWI Polar-5 aircraft). The spectral resolution of the instrument is $\sim 0.82 \mathrm{~nm}$ for $\mathrm{CH}_{4}$ and $\mathrm{CO}_{2}$ detection (between $1590 \mathrm{~nm}$ and $1690 \mathrm{~nm}$ ) and $0.46 \mathrm{~nm}$ for the detection of $\mathrm{O}_{2}(\sim 760 \mathrm{~nm})$. In the current version of the WFMD/M retrieval algorithm simultaneously retrieved $\mathrm{CO}_{2}$ columns are used to estimate the dry $\mathrm{CH}_{4}$ air columns and to account for line-of-sight errors. For overflights over strong $\mathrm{CO}_{2}$ sources (i.e. power plants) also the vice versa approach is applied and the retrieved dry $\mathrm{CO}_{2}$ air columns are calculated by normalization with the respective measured $\mathrm{CH}_{4}$ air columns. To test the instrument performance different ground based and airborne measurements on different aircrafts and on the campus of the university of Bremen have been performed. The "on-ground" tests demonstrate that the instrument is able to measure and retrieve with high precision $\mathrm{CH}_{4} / \mathrm{CO}_{2}$ profile scaling factor ratios (PSFRs) in sun illuminated target (SIT) "pseudo" nadir configuration. In this measurement geometry the instrument observed the radiance of a group of trees illuminated by the Sun. For these measurements a precision of $\sim 0.33 \%$ of the $\mathrm{CH}_{4} / \mathrm{CO}_{2}$ PSF ratio (at $0.148 \mathrm{~s}$ exposure times) can be achieved for each single detector exposure. The precision is defined as the standard deviation $(1 \sigma)$ of the retrieved PSF ratios. The according SNR for each single exposure was in the range of $\overline{\mathrm{SNR}} \approx 1600$ (Sect. 4.4). This is in good agreement with model simulations where shot noise, dark signal shot noise and readout noise of the detector are the main contributors.

A second ground test demonstrated that the instrument is able to directly measure scattered down-welling hemispheric radiance. With a spectrometer f-number of $f / 3.9$, single detector exposure times in the order of $0.7-1 \mathrm{~s}$ have been achieved in zenith sky geometry. For these measurements a single readout precision of $0.63 \%$ of the retrieved $\mathrm{CH}_{4} / \mathrm{CO}_{2}$ PSF ratios and $\overline{\mathrm{SNR}}$ values of $\sim 1200$ have been accomplished. These values were close to the results obtained by instrument model simulations (Sect. 4.4).

It was demonstrated that at an altitude of 4500 m MAMAP reaches an average single readout precision of the retrieved $\mathrm{CH}_{4} / \mathrm{CO}_{2} \mathrm{PSF}$ ratios in the range of $\sim 1.10 \%$ (for $0.058 \mathrm{~s}$ exposure time) over land targets with homogeneous radiance distribution. Assuming that changes within the concentration only occur in the $\mathrm{CH}_{4}$ column below the aircraft, this corresponds to a $\sim 0.78 \% \mathrm{CH}_{4}$ total column variation. Over water (at $4500 \mathrm{~m}$ altitude, albedo/SSR 0.01 ) with homogeneous radiance an average single readout precision of the retrieved $\mathrm{CH}_{4} / \mathrm{CO}_{2} \mathrm{PSF}$ ratios of $1.12 \%$ (for $1 \mathrm{~s}$ exposure time) can be obtained (corresponding to $\sim 0.82 \% \mathrm{CH}_{4}$ total column variation). Both PSFR precision estimates are very close to the simulated values of $0.71 \%$ for homogeneous land (LHO) and $0.83 \%$ for homogeneous water targets (WHO) as summarized in Table 3. The MAMAP precision over these types of targets is limited primarily by shot and detector noise and not affected by vibrations. The estimated airborne shortterm spectral stability for these targets is well within the requirements, even though the stability is a factor of $\sim 5.5-20$ decreased compared to ground based observations (see Table 6).

For airborne measurements over targets with inhomogeneous surface radiance, the instrument achieves a single readout precision of the retrieved PSF ratios of $2.8 \%$ (at $0.058 \mathrm{~s}$ exposure time) for land ( $\mathrm{LIH}$ ) and $2.74 \%$ (at $1 \mathrm{~s}$ exposure time) for water (WIH). Assuming changes in the $\mathrm{CO}_{2}$ column as constant and $\mathrm{CH}_{4}$ changes to occur only below the 
aircraft (altitude of $4500 \mathrm{~m}$ ), this corresponds to singe readout total column precisions of $\sim 1.98 \%$ for land (albedo/SSR $\sim 0.18$ ) and $\sim 2.0 \%$ for water (albedo/SSR $\sim 0.01$ ). These estimated precisions are a factor of 3.9 (land)-6.5 (water) lower compared to model simulations. The degraded performance for inhomogeneous illumination is attributed to smile and keystone effects of the spectrometer system's optical bench, combined with the resulting inhomogeneous illumination along the slit. Minor effects, like small spectral features in the earthshine spectral reflectance, can not be completely excluded as a reason. The assumption that the inhomogeneous slit illumination is primary responsible for the degraded performance was supported and confirmed by ZEMAX $^{\circledR}$ optical design program's end-to-end simulations of the optical system of MAMAP. The assumption is furthermore also supported by the fact, that degraded short-term spectral stability over targets with inhomogeneous radiance can be observed, as compared to those with homogeneous radiance. The origin of this stability degradation can not be traced back to vibrations or thermal changes of the optical bench. A modification of the spectrometer's optical bench incorporating a specially designed spatial scrambler unit is proposed to reduce spectral shifts and slit variations. It is expected that the precision for the $\mathrm{CH}_{4} / \mathrm{CO}_{2} \mathrm{PSF}$ ratio for each single readout can be reduced from currently $2.8 \%$ to less than $1.5 \%$. Under the assumption that the precision is barely affected by small spectral structures of the SSR, single readout precisions for the PSFR in the order of $1 \%$ remain feasible as can be demonstrated for homogeneous targets (i.e. PSFRP $=1.1 \%$ for $\mathrm{LHO}$ and $1.12 \%$ for WHO, corresponding to $\mathrm{CH}_{4}$ total column precisions of $\sim 0.75 \%$ for LHO and $\sim 0.94 \%$ for $\mathrm{WHO}$ ).

For airborne operation in co-added burst mode (BM) the instrument achieved a $\mathrm{CH}_{4} / \mathrm{CO}_{2}$ profile scaling factor ratio precision PSFRP $_{\mathrm{BM}}$ over land targets with inhomogeneous radiance (LIH) of $\sim 1.74 \%$ (10 measurements co-added) as summarized in Table 4. For a flight altitude of $4500 \mathrm{~m}$ this corresponds to a $\sim 1.23 \% \mathrm{CH}_{4}$ total column precision $(\sim 190 \mathrm{ppm} \mathrm{m})$, assuming all changes below the aircraft and $\mathrm{CO}_{2}$ as constant.

For the total co-adding time of $0.6-0.8 \mathrm{~s}$ and a cruise speed of $\sim 200 \mathrm{~km} \mathrm{~h}^{-1}$, ground scenes lengths along the flight track (LT) of 33-44 m are achieved. Overall the instrument achieves the target precision of 1-2\% total column (corresponding to $150-300 \mathrm{ppm} \mathrm{m}$ below the aircraft) for the target ground scene lengths of $<200 \mathrm{~m}$ (LT) over land for typical albedos/SSR of $\sim 0.18$. After modification of the optical bench, total column precisions $\ll 1 \%$ for ground scene lengths (LT) $<200 \mathrm{~m}$ are predicted. In that case it can be assumed that the MAMAP $\mathrm{CH}_{4}$ total column uncertainty variation will no longer be limited by the precision of the instrument but by the relative accuracy.

In 2007 several flights were performed over anthropogenic targets. It has been demonstrated that MAMAP is able to measure elevated levels of $\mathrm{CO}_{2}$ downwind from coal-fired power plants. Flights over a landfill with organic waste indicated anomalies in the retrieved $\mathrm{CH}_{4} / \mathrm{CO}_{2}$ PSFRs (see Sect. 6) within the range of $\sim 1-2 \%$, corresponding to a $\sim 0.56-1.11 \%$ concentration increase of the total $\mathrm{CH}_{4}$ column below the aircraft. From this measured anomaly and by knowledge of the wind speed, estimates of the expected fluxes were made using a simple model. With these calculations it can be estimated that the mean emission rate of the landfill for the upper central area must be in the range of $1.24-2.48 \mathrm{~g} \mathrm{~m}^{-2} \mathrm{~h}^{-1}$ or larger (see Sect. 6).

Using models of the emission, it can also be demonstrated that the achieved instrument precision of $\sim 1 \%$ total column at the high spatial resolution enables the $\mathrm{CH}_{4}$ emissions from strong local sources to be quantified. Such local sources comprise geological sources such as dry seeps and mud volcanoes, the destabilization of shallow gas hydrates, anthropogenic emissions from landfills with organic waste and fugitive emissions from oil and gas industry (i.e. well drilling and abandoned gas wells, oil sand tailings settling basins, emissions from gas and oil processing and gas compression and transport). In addition strong local $\mathrm{CO}_{2}$ sources such as coal-fired power plants and direct and sub areal emissions from volcanoes can be measured and characterized. Measurements of the emissions from strong and large areal sources such as rice paddies, tropical and Siberia wetlands, will become feasible for periods of large emissions but requires appropriate weather conditions, flight patterns and data averaging strategies. Under stable atmospheric conditions, MAMAP measurements (obtained from SWIR data only) can potentially be used for micro-, meso- and synoptic scale validation of $\mathrm{CH}_{4} / \mathrm{CO}_{2}$ column ratios obtained from daily $\mathrm{CH}_{4}$ and $\mathrm{CO}_{2}$ chemical transport model simulations, and for validation of satellite measurements. However this first requires validation of the MAMAP measurements itself.

Furthermore, MAMAP also serves as a test bed for future high spatial resolution greenhouse gas imaging sensor developments for airborne and space instrumentation, as for example the CarbonSat concept (Bovensmann et al., 2010).

Acknowledgements. We would like especially to thank Ira Leifer, University of California, Santa Barbara (USA), Torsten Sachs, German Research Centre for Geosciences (GFZ), Germany, and Oliver Schneising, University of Bremen (UB), Germany for comments and corrections on the early version of this manuscript.

We would like to thank the mechanical workshops of the German Research Centre for Geosciences (GFZ), and the University of Bremen, especially Ronny Giese (GFZ), Elke Sorgenicht (UB) and Andre Brünkers (UB) for manufacturing the mechanical parts of the MAMAP instrument.

We would like to thank our pilots, especially Carsten Lindemann from Free University Berlin (FUB) for the meteorological support during the campaigns.

MAMAP flights and ground operations were supported in different ways by the German Research Centre for Geosciences (GFZ), 
Germany; the University and State of Bremen, Germany; Institute for Space Science (ISS), Free University of Berlin (FUB), Germany; Alfred Wegener Institute for Polar and Marine Research (AWI), Germany; Enterprise Airlines, Canada; Lake Central Air Services (LCAS), Canada; Transport Canada (design approval), Canada; RWE Power AG, Germany.

Information on the actual emission of the power plant Schwarze Pumpe and Jänschwalde, Germany were provided by Vattenfall Europe Generation AG \& Co. KG, Cottbus, Germany

The solar spectrum used was obtained from NSO/Kitt Peak (http://solarnews.nso.edu) and was produced cooperatively by NSF/NOAO, NASA/GSFC, and NOAA/SEL.

Edited by: J. Notholt

\section{References}

Ackerman, K. V. and Sundquist, E. T.: Comparison of Two U.S. Power-Plant Carbon Dioxide Emissions Data Sets, Environ. Sci. Technol., 42, 5688-5693, doi:10.1021/es800221q, 2008.

Barkley, M. P., Monks, P. S., Frieß, U., Mittermeier, R. L., Fast, H., Körner, S., and Heimann, M.: Comparisons between SCIAMACHY atmospheric $\mathrm{CO}_{2}$ retrieved using (FSI) WFM-DOAS to ground based FTIR data and the TM3 chemistry transport model, Atmos. Chem. Phys., 6, 4483-4498, doi:10.5194/acp-64483-2006, 2006.

Bergamaschi, P., Krol, M., Dentener, F., Vermeulen, A., Meinhardt, F., Graul, R., Ramonet, M., Peters, W., and Dlugokencky, E. J.: Inverse modelling of national and European $\mathrm{CH}_{4}$ emissions using the atmospheric zoom model TM5, Atmos. Chem. Phys., 5, 2431-2460, doi:10.5194/acp-5-2431-2005, 2005.

Bergamaschi, P., Frankenberg, C., Meirink, J. F., Krol, M., Dentener, F., Wagner, T., Platt, U., Kaplan, J. O., Körner, S., Heimann, M., Dlugokencky, E. J., and Goede, A.: Satellite chartography of atmospheric methane from SCIAMACHY on board ENVISAT: 2. Evaluation based on inverse model simulations, J. Geophys. Res., 112, 501-511, doi:10.1029/2006JD007268, 2007.

Bergamaschi, P., Frankenberg, C., Meirink, J. F., Krol, M., Villani, M. G., Houweling, S., Dentener, F., Dlugokencky, E. J., Miller, J. B., Gatti, L. V., Engel, A., and Levin, I.: Inverse modelling of global and regional $\mathrm{CH}_{4}$ emissions using SCIAMACHY satellite retrievals, J. Geophys. Res., 114, D22301, doi:10.1029/2009JD012287, 2009.

Bohn, T. J., Lettenmaier, D. P., Sathulur, K., Bowling, L. C., Podest, E., McDonald, K., and Friborg, T.: Methane emissions from western Siberian wetlands: heterogeneity and sensitivity to climate change, Environ. Res. Lett., 2, 045015, doi:10.1088/17489326/2/4/045015, 2007.

Börjesson, G., Danielsson, Å., and Svennson, B. H.: Methane Fluxes from a Swedish Landfill Determined by Geostatistical Treatment of Static Chamber Measurements, Environ. Sci. Technol., 34, 4044-4050, 2000.

Bovensmann, H., Burrows, J., Buchwitz, M., Frerick, J., Noël, S., and Rozanov, V.: SCIAMACHY: Mission Objectives and Measurement Modes, J. Atmos. Sci., 56, 127-150, 1999.
Bovensmann, H., Buchwitz, M., Burrows, J. P., Reuter, M., Krings, T., Gerilowski, K., Schneising, O., Heymann, J., Tretner, A., and Erzinger, J.: A remote sensing technique for global monitoring of power plant $\mathrm{CO}_{2}$ emissions from space and related applications, Atmos. Meas. Tech., 3, 781-811, doi:10.5194/amt-3-781-2010, 2010.

Bowen, R. G., Dallimore, S. R., and Côté, M. M.: Geomorphology and Gas Release from Pockmark Features in the Mackenzie Delta, Northwest Territories, Canada, Proceedings 9th International Conference on Permafrost, University of Alaska Fairbanks, http://www.nicop.org/, last access: 1 February 2011, 1, 171-176, 2008.

Bréon, F.-M. and Ciais, P.: Spaceborne remote sensing of greenhouse gas concentrations, Comptes Rendus Geoscience, 342, 412-424, doi:10.1016/j.crte.2009.09.012, 2010.

Buchwitz, M., Rozanov, V. V., and Burrows, J. P.: A near-infrared optimized DOAS method for the fast global retrieval of atmospheric $\mathrm{CH}_{4}, \mathrm{CO}, \mathrm{CO}_{2}, \mathrm{H}_{2} \mathrm{O}$, and $\mathrm{N}_{2} \mathrm{O}$ total column amounts from SCIAMACHY Envisat-1 nadir radiances, J. Geophys. Res., 105, 15231-15245, 2000.

Buchwitz, M., de Beek, R., Burrows, J. P., Bovensmann, H., Warneke, T., Notholt, J., Meirink, J. F., Goede, A. P. H., Bergamaschi, P., Körner, S., Heimann, M., and Schulz, A.: Atmospheric methane and carbon dioxide from SCIAMACHY satellite data: initial comparison with chemistry and transport models, Atmos. Chem. Phys., 5, 941-962, doi:10.5194/acp-5-941-2005, 2005a.

Buchwitz, M., de Beek, R., Noël, S., Burrows, J. P., Bovensmann, H., Bremer, H., Bergamaschi, P., Körner, S., and Heimann, M.: Carbon monoxide, methane and carbon dioxide columns retrieved from SCIAMACHY by WFM-DOAS: year 2003 initial data set, Atmos. Chem. Phys., 5, 3313-3329, doi:10.5194/acp-53313-2005, 2005b.

Buchwitz, M., de Beek, R., Noël, S., Burrows, J. P., Bovensmann, H., Schneising, O., Khlystova, I., Bruns, M., Bremer, H., Bergamaschi, P., Körner, S., and Heimann, M.: Atmospheric carbon gases retrieved from SCIAMACHY by WFM-DOAS: version $0.5 \mathrm{CO}$ and $\mathrm{CH}_{4}$ and impact of calibration improvements on $\mathrm{CO}_{2}$ retrieval, Atmos. Chem. Phys., 6, 2727-2751, doi:10.5194/acp-6-2727-2006, 2006.

Burrows, J. P., Hölzle, E., Goede, A. P. H., Visser, H., and Fricke, W.: SCIAMACHY - Scanning Imaging Absorption Spectrometer for Atmospheric Chartography, Acta Astronaut., 35, 445451, 1995.

Chakraborty, S. K. and Anggraini, J.: Massive mud flow and environmental damage following drilling failure - an example from Indonesia, Petrotech - 2009, 11-15 January 2009, P09-532, 1115, 2009.

Chambers, A. and Strosher, M.: DIAL Measurements of Fugitive Emissions from Natural Gas Plants and the Comparison with Emission Factor Estimates, 15th Annual Emission Inventory Conference, US Environmental Protection Agency New Orleans, 15-18 May, 2006a.

Chambers, A. and Strosher, M.: Refinery Demonstration of Optical Technologies for Measurement of Fugitive Emissions and for Leak Detection, Final Report, Environment Canada, Ontario Ministry of the Environment and Alberta Environment, 2006b.

Chen, Y.-H. and Prinn, R. G.: Estimation of atmospheric methane emissions between 1996 and 2001 using a three-dimensional global chemical transport model, J. Geophys. Res., 111, D10307, 
doi:10.1029/2005JD006058, 2006.

Crisp, D., Miller, C., Bréon, F., Boesch, H., Braverman, A., Brown, L., Bruegge, C., Burrows, J., Chevallier, F., Ciais, P., Connor, B., Doney, S., Engelen, R., Fung, I., Griffith, D., Jacob, D., Michalak, A., Natraj, V., Notholt, J., O'Brien, D., O'Dell, C., Palmer, P., Pawson, S., Pollock, R., Polonsky, I., Randerson, J., Rayner, P., Rogers, M., Salawitch, R., Sander, S., Stephens, G., Tans, P., Toon, G., Wennberg, P., Wofsy, S., Wuch, D., and Yung, Y.: The Need for Atmospheric Carbon Dioxide Measurements from Space: Contributions from a Rapid Reflight of the Orbiting Carbon Observatory, http://www.nasa.gov/pdf/ 363474main_OCO_Reflight.pdf, last access: 1 February 2011, p. 54, 2009.

Dlugokencky, E. J., Steele, L. P., Lang, P. M., and Masarie, K. A.: Atmospheric methane at Mauna Loa and Barrow observatories: Presentation and analysis of in situ measurements, J. Geophys. Res., 100, 23103-23113, 1995.

Dlugokencky, E. J., Myers, R. C., Lang, P. M., Masarie, K. A., Crotwell, A. M., Thoning, K. W., Hall, B. D., Elkins, J. W., and Steele, L. P.: Conversion of NOAA atmospheric dry air $\mathrm{CH}_{4}$ mole fractions to a gravimetrically prepared standard scale, J. Geophys. Res., 110, D18306, doi:10.1029/2005JD006035, 2005.

EPER: European Pollutant Emission Register 2004, http://eper.ec. europa.eu/ (last access: 1 February 2011), 2004.

Ershov, O.: Pergam-Suisse ALMA System Inspection of pipelines from helicopter in the North part of Italy-Report, Pergam-Suisse AG Talacker 42 Zürich 8001, Switzerland, 2007.

Etiope, G., Feyzullayev, A., Baciu, C. L., and Milkov, A. V.: Methane emission from mud volcanoes in eastern Azerbaijan, Geology, 32, 465-468, doi:10.1130/G20320.1, 2004.

Fellner, J., Schöngrundner, P., and Brunner, P. H.: Methanemissionen aus Deponien - Bewertung von Messdaten (METHMES) (durchgeführt im Auftrag des Bundesministeriums für Landund Forstwirtschaft, Umwelt und Wasserwirtschaft), Technische Universität Wien, Institut für Wassergüte und Abfallwirtschaft, Abteilung Abfallwirtschaft und Stoffhaushalt, 1040 Wien, Austria, Karlsplatz 13226.4, 2003.

Frankenberg, C., Meirink, J., Weele, M., Platt, U., and Wagner, T.: Assessing Methane Emissions from Global Space-Borne Observations, Science, 308, 1010-1014, doi:10.1126/science.1106644, 2005.

IPCC: Climate Change 2001: The Scientific Basis, Contribution of Working Group I to the Third Assessment Report of the Intergovernmental Panel on Climate Change (IPCC), edited by: Houghton, J. T., Ding, Y., Griggs, D. J., Noguer, M., van der Linden, P. J., Dai, X., Maskell, K., and Johnson, C. A., Cambridge University Press, Cambridge, UK and New York, NY, USA, 881 pp., 2001.

IPCC: Climate Change 2007: The Physical Science Basis, Contribution of Working Group I to the Fourth Assessment Report of the Intergovernmental Panel on Climate Change, edited by: Solomon, S., Qin, D., Manning, M., Chen, Z., Marquis, M., Averyt, K. B., Tignor, M., and Miller, H. L., Cambridge University Press, Cambridge, UK and New York, NY, USA, 996 pp., 2007.

Jagovkina, S. V., Karol, I. L., Zubov, V. A., Lagun, V. E., Reshetnikov, A. I., and Rozanov, E. V.: Reconstruction of the methane fluxes from the west Siberia gas fields by the 3D regional chemical transport model, Atmos. Environ., 34, 5319-5328, doi:10.1016/S1352-2310(00)00347-2, 2000.
Jagovkina, S. V., Karol, I. L., Zubov, V. A., Lagun, V. E., Reshetnikov, A. I., and Rozanov, E. V.: Methane Fluxes in West Siberia: 3-D Regional Model Simulation, Water, Air Soil Pollut., 1, 429436, doi:10.1023/A:1013106011265, 2001.

Judd, A. G.: Natural seabed gas seeps as sources of atmospheric methane, Environ. Geol., 46, 988-996, doi:10.1007/s00254-0041083-3, 2004.

Kort, E. A., Eluszkiewicz, J., Stephens, B. B., Miller, J. B., Gerbig, C., Nehrkorn, T., Daube, B. C., Kaplan, J. O., Houweling, S., and Wofsy, S. C.: Emissions of $\mathrm{CH}_{4}$ and $\mathrm{N}_{2} \mathrm{O}$ over the United States and Canada based on a receptororiented modeling framwork and COBRA-NA atmospheric observations, Geophys. Res. Lett., 35, L18808, doi:10.1029/2008GL034031, 2008.

Krings, T., Buchwitz, M., Gerilowski, K., Tretner, A., Erzinger, J., Burrows, J. P., and Bovensmann, H.: MAMAP - A new spectrometer system for column-averaged methane and carbon dioxide observations from aircraft: Retrieval algorithm and first inversions for point source emission rates, in preparation, 2011.

Livingston, W. and Wallace, L.: An atlas of the solar spectrum in the infrared from 1850 to $9000 \mathrm{~cm}^{-1}$ (1.1 to $\left.5.4 \mu \mathrm{m}\right)$, National Solar Observatory, Tech. rep. 91-001, 1991.

Matsueda, H. and Inoue, H. Y.: Aircraft measurements of trace gases between Japan and Singapore in October of 1993, 1996 and 1997, Geophys. Res. Lett., 26, 2413-2416, doi:10.1029/1999GL900089, 1999.

Meyer, O., Busack, V., Haepe, S., Theopold, F., and Heimes, F. J.: HELPCOS The Helicopter Based Pipeline Control System of VGN - Verbundnetz AG, 23rd World Gas Conference, Amsterdam, 2006.

Miller, J. B., Gatti, L. V., d'Amelio, M. T. S., Crotwell, A. M., Dlugokencky, E. J., Bakwin, P., Artaxo, P., and Tans, P. P.: Airborne measurements indicate large methane emissions from the eastern Amazon basin, Geophys. Res. Lett., 34, L10809, doi:10.1029/2006GL029213, 2007.

Mörner, N.-A. and Etiope, G.: Carbon degassing from the lithosphere, Global Planet. Change, 33, 185-203, doi:10.1016/S0921-8181(02)00070-X, 2002.

Nisbet, E.: Methane Monitoring in the European region - MethMonitEUr, EC contract EVK2-CT-2002-00175, Coordinator: Euan Nisbet, Final Report, 2005.

NRC: National Research Council (NRC) Committee on Methods for Estimating Greenhouse Gas Emissions, Verifying Greenhouse Gas Emissions: Methods to Support International Climate Agreements, available from: http://www.nap.edu/catalog/12883. html, last access: 1 February 2011, ISBN 0-309-15212-7, 2010.

Oberlander, E. A., Brenninkmeijer, C. A. M., Crutzen, P. J., Elansky, N. F., Golitsyn, G., Granberg, I. G., Scharffe, D., Hofmann, R., Belikov, I. B., Paretzke, H. G., and van Velthoven, P. F. J.: Trace gas measurements along the Trans-Siberian railroad: The TROICA 5 expedition, J. Geophys. Res., 107, 4206, doi:10.1029/2001JD000953, 2002.

Rice, A. L., Tyler, S. C., McCarthy, M. C., Boering, K. A., and Atlas, E.: Carbon and hydrogen isotopic compositions of stratospheric methane: 1. High-precision observations from the NASA ER-2 aircraft, J. Geophys. Res., 108, 4460, doi:10.1029/2002JD003042, 2003.

Roberts, D. A., Bradley, E. S., Cheung, R., Leifer, I., Dennison, P. E., and Margolis, J. S.: Mapping methane emissions from a marine geological seep source using 
imaging spectrometry, Remote Sens. Environ., 114, 592-606, doi:10.1016/j.rse.2009.10.015, 2010.

Rothman, L., Jaquemart, D., Barbe, A., Benner, D. C., Birk, M., Brown, L., Carleer Jr., M. C. C., Chance, K., Coudert, L., Dana, V., Devi, V., Flaud, J.-M., Gamache, R., Goldman, A., Hartmann, J.-M., Jucks, K., Makim, A., Mandin, J.-Y., Massie, S., Orphalh, J., Perrin, A., Rinsland, C., Smith, M., Tennyson, J., Tolchenov, R., Toth, R., Auwera, J. V., Varanasi, P., and Wagner, G.: The HITRAN 2004 molecular spectroscopic database, J. Quant. Spectrosc. Ra., 96, 139-204, doi:10.1016/j.jqsrt.2004.10.008, 2005.

Rozanov, A., Rozanov, V., Buchwitz, M., Kokhanovsky, A., and Burrows, J.: SCIATRAN 2.0 - A new radiative transfer model for geophysical applications in the $175-2400 \mathrm{~nm}$ spectral region, Adv. Space Res. 36, 1015-1019, doi:10.1016/j.asr.2005.03.012, 2005.

Sachs, T., Giebels, M., Wille, C., Kutzbach, L., and Boike, J.: Methane Emissions from Siberian Wet Polygonal Tundra on Multiple Spatial Scales: Vertical Flux Measurements by Closed Chambers and Eddy Covariance, Samoylov island, Lena River Delta, Proceedings of the 9th International Conference on Permafrost, University of Alaska, Fairbanks, 29 June-3 July 2008, 1549-1554, 2008.

Schneising, O.: Analysis and interpretation of satellite measurements in the near-infrared spectral region: Atmospheric carbon dioxide and methane, $\mathrm{PhD}$ thesis, University of Bremen, Institute of Environmental Physics (IUP), Germany, 2009.

Schneising, O., Buchwitz, M., Burrows, J. P., Bovensmann, H., Reuter, M., Notholt, J., Macatangay, R., and Warneke, T.: Three years of greenhouse gas column-averaged dry air mole fractions retrieved from satellite -Part 1: Carbon dioxide, Atmos. Chem. Phys., 8, 3827-3853, doi:10.5194/acp-8-3827-2008, 2008.

Schneising, O., Buchwitz, M., Burrows, J. P., Bovensmann, H., Bergamaschi, P., and Peters, W.: Three years of greenhouse gas column-averaged dry air mole fractions retrieved from satellite - Part 2: Methane, Atmos. Chem. Phys., 9, 443-465, doi:10.5194/acp-9-443-2009, 2009.

Shakhova, N., Semiletov, I., Salyuk, A., Yusupov, V., Kosmach, D., and Gustafsson, Ã.: Extensive Methane Venting to the Atmosphere from Sediments of the East Siberian Arctic Shelf, Science, 327, 1246-1250, doi:10.1126/science.1182221, 2010.

Shakhova, N. E., Semiletov, I. P., Salyuk, A. N., Bel'cheva, N. N., and Kosmach, D. A.: Methane anomalies in the near-water atmospheric layer above the shelf of East Siberian Arctic shelf, Dokl. Earth Sci., 415, 764-768, doi:10.1134/S1028334X07050236, 2007.
Siddique, T., Gupta, R., Fedorak, P. M., MacKinnon, M. D., and Foght, J. M.: A first approximation kinetic model to predict methane generation from an oil sands tailings settling basin, Chemosphere, 72, 1573-1580, doi:10.1016/j.chemosphere.2008.04.036, 2008.

Suto, H., Kuze, A., Nakajima, M., Hamazaki, T., Yokota, T., and Inoue, G.: Airborne SWIR FTS for GOSAT validation and calibration (Proceedings Paper), SPIE Proceedings, 7106, doi:10.1117/12.799963, 2008.

Takeuchi, W., Tamura, M., and Yasuoka, Y.: Estimation of methane emission from West Siberian wetland by scaling technique between NOAA AVHRR and SPOT HRV, Remote Sens. Environ., 85, 21-29, doi:10.1016/S0034-4257(02)00183-9, 2003.

Villani, M. G., Bergamaschi, P., Krol, M., Meirink, J. F., and Dentener, F.: Inverse modeling of European $\mathrm{CH}_{4}$ emissions: sensitivity to the observational network, Atmos. Chem. Phys., 10, 1249-1267, doi:10.5194/acp-10-1249-2010, 2010.

Watson, R. T., Rohde, H., Oescherger, H., and Siegenthaler, U.: Greenhouse gases and aerosols, in: Climate Change: The intergovernmental Panel on Climate Change Scientific Assessment, edited by: Houghton, J. T., Jenkins, G. J., and Ephraumus, J. J., Cambridge University Press, Cambridge, 1-40, 1990.

Winderlich, J., Chen, H., Gerbig, C., Seifert, T., Kolle, O., Lavric, J. V., Kaiser, C., Höfer, A., and Heimann, M.: Continuous lowmaintenance $\mathrm{CO}_{2} / \mathrm{CH}_{4} / \mathrm{H}_{2} \mathrm{O}$ measurements at the Zotino Tall Tower Observatory (ZOTTO) in Central Siberia, Atmos. Meas. Tech., 3, 1113-1128, doi:10.5194/amt-3-1113-2010, 2010.

Wuebbles, D. J. and Hayhoe, K.: Atmospheric methane and global change, Earth-Sci. Rev., 57, 177-210, doi:10.1016/S00128252(01)00062-9, 2002.

Yoshida, J., Kawashima, T., Ishida, J., Hamada, K., Tanii, J., Katsuyama, Y., Suto, H., Kuze, A., Nakajima, M., and Hamazaki, T.: Prelaunch performance test results of TANSOFTS and CAI on GOSAT (Proceedings Paper), Proc. SPIE, 7082, doi:10.1117/12.800701, 2008.

Zimig, W. and Ulbricht, M.: CHARM ${ }^{\circledR}$ - The dawn of a new era in checking the tightness of natural gas pipelines, 23rd World Gas Conference, Amsterdam, 2006. 